\title{
BIOLOGÍA, MEDICINA Y EUGENESIA EN URUGUAY
}

\author{
Juan Pedro Barrán \\ Profesor de Historia del Uruguay - Instituto de Ciencias Históricas \\ Facultad de Humanidades y Ciencias de la Educación - Universidad de la Republica (Uruguay)
}

\section{RESUMEN}

En este trabajo se analizan las profundas relaciones entre biología, medicina y sociedad que se establecieron en el Uruguay a lo largo del siglo XIX así como el proceso de medicalización y biologización del pensamiento social que se produce a lo largo de las primeras décadas del siglo XX, y el papel que jugaron en ese proceso las ideas eugénicas y los defensores de la eugenesia.

\section{SUMMARY}

In this work are analyzed the deep relationships between biology, medicine and society that were settled down in the Uruguay along the XIX century as well as the process of «medicalization» and «biologization» of the social thought that take place along the first decades of the XX century, and the role that played the eugenic ideas and defenders of eugenics in that process.

\section{LA MORAL BIOLÓGICA.}

En el libro Medicina y Sociedad en el Uruguay del Novecientos ${ }^{1}$, del que forma parte este trabajo, hemos analizado de qué manera el orden establecido se infiltraba en el saber médico y, así, biología y psiquiatría coaligadas, definían al placer como un hecho legítimo a la par que imprescindiblemente controlable, y al hombre burgués como encarnación de la acción, el dominio y la normalidad mental.

En este trabajo comenzaremos a exponer el revés de esta trama. Observaremos los primeros intentos de fundar normas éticas, sociales, políticas y culturales a partir del saber médico, como si este fuera el único fundamento posible de una cultura laicizada que había hecho del culto a cierta clase de salud su gran fuente de valores.

1 BARRÁn, José Pedro, (1995), Medicina y Sociedad en el Uruguay del Novecientos, Montevideo, Ediciones de la Banda Oriental,. Esta obra se compone de tres volúmenes: 1.- El poder de curar; 2.- La ortopedia de los pobres; 3.- La invención del cuerpo. El trabajo que se presenta es parte de este tercer volumen, pp. 175-225. 
Las primeras incursiones del saber médico en el campo de la normativa social se parecieron, sospechosamente, como veremos, a una reafirmación del statu-quo. Los antiguos pecados cristianos que se habían trasmutado en transgresiones a la moral burguesa, ganaron nueva legitimidad cuando se convirtieron en caldo de cultivo de la enfermedad o en ella misma. Observemos, a vía de ejemplo, lo sucedido con el ocio. La vieja acidia medieval se refería a la negligencia del hombre en cumplir sus deberes religiosos: la burguesía la transformó en pereza, el descuido de los intereses propios; a su vez, el saber médico de fines del siglo XIX la convirtió en origen de la enfermedad. En 1881, el pedagogo Francisco A. Berra publicó sus Nociones de Higiene y allí usó un argumento extraído del culto a la salud y el saber médico para fundamentar su condena a la pereza:

\footnotetext{
«así como es inconveniente trabajar demasiado, lo es el no trabajar bastante, pues entonces los órganos musculares y nerviosos no atraen hacia sí los elementos nutritivos de la sangre, en la cantidad necesaria para su conservación y desarrollo, sino que pasa por ellos el fluido circulatorio llevándose consigo cuanto traía desde los pulmones. Es decir que se nutren en proporciones tanto más escasas cuanto menor es el ejercicio. De aquí resultan la debilidad general [...] la manía y, por fin, una muerte prematura. Tales son los terribles efectos de la acción escasa, de la haraganería [...] combate la pereza [...] porque es el más terrible enemigo ${ }^{2}$ ».
}

En realidad aquella cultura pretendió extraer su moral del cuidado de la salud, porque sus integrantes cada vez estaban más convencidos de que debían vivir casi exclusivamente en función de ella y que de ella debían partir las conductas legítimas. Prueba de ello es que, en el Novecientos, la Iglesia Católica comenzó a advertir que la invocación de la salud era un poderoso argumento a utilizar para fortalecer su condena del pecado; para alejar a los fieles del Diablo no bastaba con asegurar que el pecado traería la perdición del alma, ahora debía agregarse que el pecado también perjudicaba — suprema ironía-la sede del placer, el cuerpo.

Todos los moralistas se plegaron a este argumento. Cuidar la salud era el leitmotiv de los textos de higiene; en esta época pasó a figurar también en los textos y periódicos religiosos. El sacerdote jesuíta Elías Reyero en su Devocionario de 1902, creyó conveniente añadir a sus comentarios morales al sexto mandamiento («no fornicar»), este otro: «Según opinión de los médicos, los pecados contra este mandamiento y la asistencia a los bailes, llevan al sepulcro a muchisimas personas ${ }^{3} »$. En 1909, Victorio Loyódice, de la Congregación del Santísimo Redentor, escribió un libro teológico de divulgación sobre El reinado de Satanás. Su visión casi medieval del combate entre las virtudes y los vicios no le impidió señalar a sus lectores que «la

2 BerRA, F.A., (1881), Nociones de Higiene, Montevideo, Barreiro y Ramos, p. 35.

3 REYERO, Elías S.J., P., (1902), Manual Católico. Devocionario. Madrid, 2 ed. S. Calleja, p. 136. 
ciencia médica declara [...] y confiesa que este vicio de la impureza causa varias y admirables enfermedades, resultado en parte de un funesto contagio, y en parte de la intemperancia misma ${ }^{4}$. Por ello no es de extrañar que el periódico ultramontano $E l$ Demócrata declarara en 1933 que «el baile moderno es condenado por la Moral católica, por los médicos y por los literatos ${ }^{5} »$. En apretada síntesis: el pecado lleva a la enfermedad y la virtud a la salud.

La medicalización de la moral católica probaba el avance espectacular de la cultura secular y su expresión más radical: el culto a la salud. La antigua preocupación por la salvación del alma había sido sustituída por la nueva, el cuidado del cuerpo. En 1885, un médico francés, Jules Rochard, advirtió este cambio y lo expresó con convicción de militante racionalista: «En las sociedades donde el nivel de riqueza se eleva, el de las creencias baja, donde el cuidado de la vida futura y el del dinero mismo pasan a segundo rango, el deseo de pasarlo bien y de morir lo más tarde posible se colocan en primer lugar; ahora bien, es la higiene sola que puede satisfacerlo6»».

El culto a la salud penetró también en el seno de la utopía secular del Novecientos que prometía la felicidad universal: la Revolución Social. La preocupación por la salvación política de los cuerpos a través de la Revolución llegó a menudo a vincularse, en anarquistas y socialistas, a la preocupación por la salud y el vigor del cuerpo. Solo los sanos serían buenos revolucionarios, no los alcoholistas ni los tuberculosos. Léase esta reflexión de un periódico anarquista de Montevideo en 1905: «Así como la cuestión de dominio y de fuerza entre las naciones, los pueblos y las razas, es, a la postre, cuestión de higiene [...] así también [...] la cuestión de la rebeldía es cuestión de glóbulos rojos, de hierro sanguíneo [...] quitar vigor a nuestro cuerpo, es quitar fuerza a la Revolución, pues solo los fuertes se niegan a ser esclavos ${ }^{7} »$. Por ello fue por lo que el líder naturalista de los anarquistas uruguayos, Antonio Valeta, escribió en 1918: «Extirpada de raíz la plaga del alcoholismo, los obreros, libres del flagelo, sabrían defender mejor sus deberes de hombre [...]. La emancipación de los trabajadores no llegará a ser un ideal de redención mientras predominen los vicios, las malas costumbres y la falta de higiene general ${ }^{8}$ ». En síntesis: sólo los sanos podrían transformar la sociedad y preparar el porvenir.

La medicalización de los dos mundos ideológicamente más contrapuestos —el católico y el anarquista- y sus respectivas utopías, testimonia la fuerza con que había penetrado el culto a la salud en el Novecientos y cómo él era el verdadero sig-

\footnotetext{
4 Victorio LoYódice, P., (1909), El reinado de Satanás, Montevideo, Tip. Martínez, p. 109-110.

5 El Demócrata, periódico de Montevideo, 21 de febrero 1933, p. 3, «El Baile moderno». Debo el conocimiento de este artículo a Rodolfo Porrini, a quien lo agradezco.

6 Cfr. LEONARD, J. (1978), La France médicale au XIXe siècle, París, Gallimard, pp. 174-175.

7 Cfr. Rodolfo Porrini: «Inmigrantes españoles y sindicalismo en Uruguay, 1905-1942», inédito, cuya consulta agradezco a su autor.

8 VALETA, Antonio, (1918), El naturalismo en el hogar, Montevideo, pp. 36-37.
} 
no de la modernidad y del cambio de valores que estaba ocurriendo. Los católicos prometían a los buenos la salud, y los anarquistas prometían a los hombres sanos la utopía igualitaria. De este modo, la salvación del alma, el más allá católico, y la Revolución Social, el más allá anarquista, sólo podrían percibirse y realizarse a través de la salud. No es de extrañar que el saber médico del Novecientos quisiera derivar de ella el bien, y de la enfermedad, el mal.

En sus principios, como adelantamos, la moral basada en la biología procuró solo legitimar a la antigua moral tradicional poniéndola de acuerdo con la nueva fuente de valores que era la salud. Pero la evolución no se detuvo aquí. El culto a la salud tenía, como todo culto, tendencias monoteístas y exclusivistas, y la creciente secularización de los valores no hizo más que reforzar su influencia. Por ello la salud, tal cual la entendía el saber médico, tendió a generar sus propios valores, no siempre concordantes con los de la vieja moral cristiana. La doctrina eugenésica, como observaremos más adelante, significó, desde este ángulo, la primera tentativa de crear una moral y una política social basadas exclusivamente en la biología.

El saber médico, empero, logró su éxito más rotundo no tanto en el plano de la formulación ideológica de valores y programas políticos, como en el plano de la recomendación y diabolización de conductas. El comportamiento más elogiado fue la escucha morosa y amorosa del propio cuerpo y sus mínimos rumores; la medicina preventiva lo convirtió en la máxima virtud del hombre contemporáneo, la única que le podía garantizar el bien supremo: la vida larga. La conducta más criticada fue aquella que descuidaba la salud. La relación del hombre con su cuerpo se recreó y su vigilancia pasó a ser el centro de las prescripciones tanto personales como colectivas, y la fuente de los valores éticos.

\subsection{Una moralidad fundada en nociones científicas}

Los médicos positivistas —probablemente la mayoría de «la clase médica» en el Novecientos- sostuvieron que la moral debía basarse en la biología y la higiene, entendida esta última como la ciencia cuidadora y preservadora de la salud. El fundamento ético de la tan buscada moral laica sustitutiva de la religiosa se hallaría en los principios que constituían la salud, el bien supremo. Y como ese bien individual dependía de lo social y a su vez lo regía, la higiene debía dirigir la acción de los gobiernos. Dos médicos batllistas del Novecientos expusieron con calor estas convicciones. Mateo Legnani lo hizo en sus Ensayos de higiene social de 1915, el sugestivo Catecismo de higiene de 1917 y el Esbozo de higiene integral de 1918. Santín Carlos Rossi realizó en 1919 una exposición rigurosa de todos los principios morales que derivaban de la biología en El Criterio Fisiológico. Mateo Legnani estimó de tal importancia este aporte de su colega y correligionario político, que cuando fue electo 
diputado presentó a su Cámara un proyecto de ley de un solo artículo, declarando «obligatorio el estudio de El Criterio Fisiológico en todos los institutos de Enseñanza Secundaria y Normal de la República».

Los razonamientos de ambos médicos escritores eran de una lógica impecable si se aceptaba el presupuesto: la culminación del saber humano en la ciencia positiva. Los antiguos gobiernos «teocráticos» habían impuesto «la orientación moral colectiva» a través de «una religión»; los gobiernos «democráticos» debían «obtener una preceptiva moral del Parlamento» y éste, «inspirarse en la ciencia». «La irreligiosidad del presente», seguramente mayor en «el porvenir», «la heterogénea mezcla de despojos de doctrinas filosóficas y religiosas» que predominaban en el Uruguay, «la laguna moral de la escuela laica, laguna no llenada al expulsar de ella las vetustas religiones positivas insoportables en la enseñanza de un pueblo culto», todo ello debía colmarse «con una moral inteligente, la que surge de la doctrina evolucionista que no excluye, por cierto, la idea de Dios». De este modo, los padres no se quejarían más, «en las tertulias familiares», de que en las escuelas públicas no se enseñase ya —desde 1909- ninguna religión; una nueva, «la de la salud», sustituiría los «prejuicios» del catolicismo ${ }^{9}$.

Santín Carlos Rossi añadió un nuevo argumento: la ventaja de la ciencia sobre la religión era que «sus afirmaciones son demostrables y obligan a la convicción, mientras las religiosas dependen de la fe, y nadie está obligado a tener fe». «La vida fisiológica [se hacía] amar sin esfuerzo» y comprender por la razón: era un hecho brutal e indiscutible ${ }^{10}$. La opinión católica de la época sostenía que una moral laica sólo conduciría al fomento sin cortapisas del placer, pues ¿qué frenos podrían establecerse que no fueran los derivados del preferir a Dios y no a sí mismo? La relación de la «moral fisiológica» con el placer es la piedra de toque de su originalidad y a la vez su tradicionalismo.

El entronizamiento de la salud podía conducir a la afirmación ilimitada de los derechos del cuerpo, a la identificción de las sensaciones del placer y satisfacción con la salud física y mental. Pero el saber médico, un saber disciplinante, luchó por convertir el gozoso hartazgo post-coito de origen popular, en la tristeza post-coito de los

9 LEGNANI, Mateo, (1922), Proyectos de higiene, Montevideo, Mercant, Tomo I, pp. 17-21; Boletín del Consejo Nacional de Higiene. (BCNH), agosto 1925, p. 594. «Proyecto de ley del diputado Mateo Legnani». LEGNANI, Mateo, (1917), Catecismo de higiene, Montevideo, Dornaleche, pp. 12-13 y 38-39.

10 Rossi, Santín C., (s.f.), El Criterio Fisiológico, Tip. Montevideo, Moderna, pp. 222-223. El postulado de una moral basada en la higiene tenía, según Mateo Legnani, antecedentes ilustres. Tolstoi, «en las escuelas de Jasnaia», había sido «un apóstol de la higiene» y «la literatura, novela y drama, que reconoce por jefe a Emilio Zola» vislumbraba esa solución «como único desenlace liberador». Una cita de Ibsen completó la trinidad bajo la cual se colocó la «moral fisiológica» predicada por este médico uruguayo. Los tres personajes literarios gozaban de inmenso prestigio en la intelectualidad liberal y aun socialista, signada toda ella por el anticlericalismo que caracteriza este planteamiento. $C f r$. LEGNANI, Mateo (1917), pp. 155-156. 


\section{JUAN PEDRO BARRÁN}

filósofos, y lo logró. La salud demostró ser, en efecto, un Dios tan exigente de sacrificios del deseo como el Dios cristiano.

La salud implicaba la subordinación del placer personal inmediato, primero, a la vida larga, y segundo, a los intereses de la sociedad que eran, en realidad, los de la "raza" humana. Así se reconstruyó la noción del deber. La afirmación del ideal ético de la vida larga fue realizada mediante la condena sin atenuantes de la vida intensa. Era mentira, afirmaba Mateo Legnani en 1915, que la genialidad fuera el fruto de la enfermedad, existía a pesar de la enfermedad: «Los achaques de Voltaire no son las causas de su fecundidad y talla intelectual», como afirmaban, románticamente, literatos y poetas. La salud y la vida larga eran, en realidad, la condición del genio: «Victor Hugo, rey de la literatura, fue sano. Goethe, privilegiado espíritu de poeta y de sabio, fue sano. Sano fue Bismarck. Los fanáticos de la vida intensa [los] mártires de la vida intensa [eran] inteligencias que suelen disiparse en el café, frente a la copa de ajenjo, en las mesas de redacción [...] en lupanar [...] rutinarios entusiastas de París [y] fanáticos de todo lo artificioso». En verdad. concluyó: «La enfermedad no perdona a los que viven intensamente ${ }^{11} »$. «La moral fisiológica» prometía vivir largamente, y ello no solo se lograba regulando el deseo en pro de la pasión serena. Los «excesos», he aquí el mal en estado de pureza patológica. El placer personal también debía subordinarse a la perpetuación de la «raza» humana. En 1919 el solidarismo batllista de Santín Carlos Rossi lo expresó en términos que quiso científicos:

\footnotetext{
«La Biología humana dice al hombre: si tú quieres vivir verdaderamente, vivir según la ley natural y científica de tu especie, si quieres que la sociedad viva y prospere, tú debes [...] olvidar tu interés inmediato y tu placer personal para no ver más que el interés y el porvenir de la humanidad, frente a la cual tú tienes deberes estrictos».
}

Pero Santín Carlos Rossi era un reformador social y también sostuvo que si el hombre moderno prefería su placer a cumplir su deber social era porque la sociedad «estaba mal organizada»: luchando por su reorganización, el hombre encontraría para su placer un lugar preciso en el todo social y contribuiría así a fortalecer la especie. Debían reformarse las formas vigentes del amor -el noviazgo y el matrimonio burgués - y de este modo liberar con prudencia el deseo, demasiado encorsetado por la moral tradicional. Los «instintos» debían doblegarse desde la razón, desde el interés de la especie, y no desde los mandatos autoritarios y a menudo vacíos de contenido biológico del Dios católico ${ }^{12}$.

En 1917 y 1918, Mateo Legnani se convirtió en un exponente extremo de la «moral fisiológica» al identificar enfermedad con mal y salud con bien. En el cuerpo sano

11 Legnani, Mateo, (1915), Ensayos de higiene social, Montevideo, Dornaleche, pp. 9-11.

12 Rossi, Santín C. (S.f.), pp. 218-221. 
solo cabía la bondad; en el enfermo, la maldad o la predisposición a ella «no [había] faltas y pecados debidos a la salud del cuerpo; no [había] dolencias debidas a [la] bondad del alma». Las virtudes derivaban del «organismo sano». El «coraje», por ejemplo, nacía «de la vitalidad, de la tonicidad de un espíritu correspondiente a un organismo sano»; «la generosidad, la cordura, la prudencia, la energía de carácter, la nobleza y la dignidad», representaban la exteriorización espiritual «de un equilibrado y vigoroso organismo».

Los vicios, en cambio, provenían del cuerpo enfermo. «El antiguo aforismo, temed a los enfermos, encierra la mayor realidad práctica; la enfermedad es el factor oculto a menudo, pero frecuentemente comprobado si se investiga, de los actos punibles». Es que «el ensimismamiento, la imprevisión, volubilidad, impulsividad y abulia [caracterizaban] a los débiles, la perversidad [a] los leprosos, la hipocresía [a] los castrados y eunucos».

A partir de sus observaciones clínicas, Mateo Legnani elaboró una lista de las enfermedades y los respectivos vicios que había encontrado en sus pacientes:

«Usurero, orgulloso, inaccesible a la piedad: herniado, litiásico, dispéptico. Cobarde en su infancia y aun hoy, chismoso, avaro, hipócrita, calumniador, privado de todo sentido moral: neurópata e hijo de alcohólico. Muy mal pagador, avaro: tuberculoso, otitis media doble. Inepto, perezoso, tímido con exceso: tuberculoso incipiente. Inepto, perezoso, afeminado: sifilítico, hijo de sifilítico. Calumniador, avaro: hepático y hemorroidario».

Esto no significaba, añadía Legnani, una relación de causa y efecto «entre lo de calumniador, y lo de hepático, entre lo de avaro y hemorroidario», pero sí la afirmación de que la enfermedad en sentido genérico podía por sí misma generar «envidia [y] actos malvados» y, además, ser «causa secundaria o concausa» del abandono del trabajo y la búsqueda desesperada de dinero, «un verdadero espoleo de las facultades incitándolas a seguir extraviados andurriales». ¿Acaso enfermedad y miseria coaligados no eran caldo de cultivo del delito?

Los ejemplos de Mateo Legnani probablemente fuesen ingenuos también a los ojos de sus contemporáneos, pero denotan su firme creencia en la enfermedad como nuevo diablo y la salud como nuevo Dios, aquello mismo que Florencio Sánchez tradujo a su manera en la obra teatral de 1907 titulada Los derechos de la salud. Léanse estos dos breves relatos de Legnani:

«He visto un hombre de campo, que era activo, valiente, experto en su trabajo. Después de un grave ataque de apendicitis, seguido de intervención quirúrgica, cambió de manera de ser, se hizo pusilánime, holgazán, chambón».

El otro caso revela mayor lógica y, sobre todo, una lógica muy uruguaya: 


\title{
JUAN PEDRO BARRÁN
}

\begin{abstract}
«En una reunión de individuos entre quienes conversaba, una vez giró la charla sobre las enfermedades y resultó que cuatro de ellos habían sufrido intervenciones quirúrgicas graves. Los cuatro eran empleados públicos, en mérito de la actuación política de cada uno, y habían caído en la política electoral desde que su estado de convalecencia ad vitam los había inutilizado para el trabajo físico».
\end{abstract}

Resumió de este modo su tesis: el moralista debía tener en cuenta que para salvar a un individuo de la «crápula» de su condición de proxeneta, más valía curarlo «de su prostatitis crónica, que lo mantiene en permanente estado de excitabilidad sexual», que predicarle el Evangelio ${ }^{13}$.

Si el planteamiento de Mateo Legnani de que la enfermedad conducía al mal puede parecernos una deducción excesiva de la «moral fisiológica», la viceversa, que también es una consecuencia de esa moral, es probable que nos parezca más sensata, porque es la creencia de muchos de nosotros en la actualidad: el mal es susceptible de ser encarado como enfermedad.

El siglo XVIII incorporó al terreno de las enfermedades, la locura, la sífilis y la masturbación, anteriormente juzgadas como posesiones diabólicas, crímenes, condignos castigos físicos del vicio, o simples males morales. Adolfo Brunel en el Montevideo de 1862 ya advertía de la novedad que había introducido su compatriota Pinel al liberar a los locos de sus cepos en 1793: «El demente ya no es considerado como un malhechor que sea necesario cargar de cadenas y arrojar en un calabozo confundiéndolo con los criminales: es un enfermo ${ }^{14}$ ». En 1923, el médico Héctor del Campo recordó a los espíritus religiosos que consideraban la enfermedad venérea como un castigo al pecado cometido, «que era más bien una desgracia que una falta $^{15}$ ». La psiquiatría positivista del italiano Cesare Lombroso (1836-1909) sobre todo, intentó transformar al criminal en un enfermo. El Novecientos uruguayo, como ya hemos comprobado, hizo suyo este punto de vista. Mateo Legnani fue terminante: «La mayoría de los delincuentes que escarnecen la ley, son enfermos ${ }^{16} »$. El psiquiatra Bernardo Etchepare halló en 1912 que la mayoría de los criminales eran «imbéciles de nacimiento» 0 «locos» ${ }^{17}$.

La transformación de toda maldad en enfermedad es un aserto que inicia en el Novecientos su brillante carrera, esa que, tal vez, recién hoy en día esté llegando a su clímax.

13 LEGNANI, Mateo, (1918), Esbozo de una higiene integral, Montevideo, Dornaleche, pp. 21 y 73-74.

14 BRUNEL, Adolfo, (1862), Consideraciones sobre la higiene y observaciones relativas a la de Montevideo, Montevideo, La Reforma Pacífica, pp. 284-288.

15 DEL CAMPO, Héctor, (1923), «Informe», Boletín del Consejo Nacional de Higiene, febrero, p. 528.

16 LEGNANI, Mateo, (1917), pp. 42-56.

17 ETCHEPARE, Bernardo, (1912), Los débiles mentales, Montevideo, Tipografia Administración de Loterías, pp. 863-864. 


\title{
BIOLOGÍA, MEDICINA Y EUGENESIA EN URUGUAY
}

En 1918, Mateo Legnani relató una historia en que la maldad está explicada por la enfermedad:

\begin{abstract}
«Es un muchacho de aspecto casi repulsivo [...]. Carece de talento. [Es feo] y el amor parece que le estuviera vedado. Hasta en el prostíbulo mal se disimula la antipatía que provoca. Cae en el alcoholismo [...]. Sus manos ya tiemblan. Se hace periodista de los de campañas terribles, calumnia [...] persigue, descarga su revólver reaccionando excesivamente contra ofensas que ha adivinado, porque en el fondo es verdad que todos desean verle hundido. El médico lo examina: encuentra que la causa primera residía en el espermatozoide, en el óvulo, en el útero, quizás en las circunstancias que rodearon la gestación de aquel pobre hombre deforme ${ }^{18}$ ».
\end{abstract}

Los anarquistas creyeron también en esta medicalización de la maldad y el crimen. En 1937, su periódico Resurgimiento sostuvo que esa posición era progresista, científica y libertaria, todo a la vez:

«Los anarquistas que ven en la carcel la fábrica de criminales más completa, que creen que al delincuente no se le regenera en esos antros de tortura [...] sino que se les debe curar, pues enfermos son, bajo la mirada y la atención de médicos psiquiatras, en hospitales ${ }^{19}$ ».

Pero en el Novecientos todavía se advierten resistencias a esta transformación de la maldad en patología, pues la moral tradicional la juzga, probablemente de manera equivocada, una disculpa que puede concluir en la disminución del castigo a los delincuentes. Es que al Novecientos le cuesta creer que la maldad pueda explicarse de otra manera que no sea la del ejercicio de la voluntad criminal, por lo menos en alguna medida ${ }^{20}$. La transformación del criminal en enfermo, auspiciada por Césare

18 LEGNANI, Mateo, (1918), p. 121.

19 PORRINI, Rodolfo, (1994), Derechos humanos y dictadura terrista, Ed. Vintén, Montevideo, p. 102. Cita en el texto del periódico anarquista y su artículo.

20 La tendencia a la psiquiatrización del mal era muy fuerte, pues concordaba con la creciente medicalización de la sociedad y la ética, y por ello se impuso en el saber médico. Observemos la evolución, ejemplar a este aspecto, del juicio social y médico sobre el castigo de los niños. En 1916 la Revista Cátedra Escolar todavía consideraba el castigo físico a los niños «en la cabeza [una] práctica viciosa [que los] embrutece y atonta» y que padres y maestros debían abandonar (Cátedra Escolar, «No castigar a los niños en la cabeza», Montevideo, n. 15, junio 15 de 1916. Debo el conocimiento de esta publicación a Esther Ruiz, a quien agradezco). Casi 80 años después, en 1993, el «maltrato» a los niños se ha convertido en una figura psicológica, que debe ubicarse dentro de esa «privación desde el punto de vista afectivo» a que someten a sus hijos determinados padres. Estos, a su vez, actúan malvadamente porque son enfermos. La maldad tal vez exista todavía, pero al haberse explicado científicamente se la comprende y deja de poseer la condición diabólica de la antigua malignidad. La voluntad del sujeto actúa dentro de un contexto patológico, no es enteramente libre. Pero la sociedad no postula la inacción frente a estos seres malos y enfermos: al viejo castigo carcelario se le debe agregar el tratamiento psiquiátrico o psicoanalítico. La médica Beatriz Estable explica así la conducta de los padres castigadores: «crecieron con fallas muy precoces, soledad y abandono, con falta de protección, estuvieron sujetos a múltiples cambios, y 
Lombroso, no extinguió la culpa, la transformó. Para Lombroso la causa de la criminalidad, residía en los «vicios» populares por excelencia, el alcoholismo y el libertinaje sexual, responsables de las taras que se poseían y se trasmitían a los hijos, taras que estaban siempre detrás de la locura delictiva, de aquella «epilepsia psíquica» que fue su creación. Así se produjo el inesperado resultado de que, otra vez, el Manicomio albergase «criminales», pero esta vez llegasen por indicación médica. Si la maldad y el delito derivaban de la enfermedad, combatirlos no consistía solo en penar y encarcelar, sino también en tratar clínicamente y hospitalizar. En el Novecientos, incluso algunos creyeron que no había tanta distancia entre el universo concentracionario edificado por la medicina para curar las enfermedades graves, formado por el Manicomio y el Hospital.

En 1917, Mateo Legnani percibió un nexo entre todas esas instituciones al sostener que si los enfermos no estuvieran hospitalizados se lanzarían al crimen y el vicio. Radical como siempre, afirmó:

\footnotetext{
«Fácil es ignorar todo el mal que producirían los enfermos que hoy ocupan los hospitales y asilos, si estuvieran desamparados. No me limito a recordar los de los manicomios. Me refiero a los de todas las clínicas. Los que no murieron enseguida, cerradas ante ellos todas las vías de existencia honradas por carecer de condiciones, se lanzarían al vicio, a la vagancia [...] al crimen. Con esta consideración basta pensar que los hospitales y asilos realizan por lo menos tanto bien como el de las cárceles ${ }^{21_{»}}$.
}

En 1911, Bernardo Etchepare, de pensamiento menos bizarro, estuvo sin embargo de acuerdo en que las cárceles debían ser lugares medicalizados, «sitios de enmienda y de reforma de la personalidad» tanto como de «sanción, [la] que después de todo, es también una terapéutica ${ }^{22}$ ». El hospital-cárcel de Legnani podía perfectamente darse la mano con la cárcel-hospital de Etchepare. Esas instituciones eran intercambiables porque la enfermedad se había convertido en la cuna de la maldad y ésta en enfermedad.

fueron criados la mayoría de las veces por diferentes figuras sustitutas, deprivados de un maternaje básico» (ESTABLE, Beatriz, (1933), «El niño maltratado y su entorno familiar», Midu, Montevideo, n. 17, octubre). Lo que antes era maldad y pecado es ahora eso y, para el saber médico, es sobre todo conducta anormal. Y si nos parecía ingenua la posición de Legnani cuando atribuía la maldad del joven feo y calumniador a los defectos del espermatozoide (en realidad, estaba pensando en una tara alcohólica), ya no nos parece tan ingenua la posición de la psicóloga actual cuando responsabiliza del mal a las infancias perversas o los inconscientes malditos. La evolución se ha cumplido y culminado: el mal se ha explicado y tornado enfermedad. La «Moral fisiológica» ha triunfado. Por eso ciertos psicoanalistas de origen judío sienten cierto malestar cuando leen explicaciones psicoanalíticas de los furores del Führer...

21 LEGNANI, Mateo, (1917), pp. 42-56.

22 ETCHEPARE, Bernardo, (1911), «La responsabilidad en los alienados», Revista Médica del Uruguay, (Organo de la Sociedad de Medicina de Montevideo), pp. 57-72. 


\subsection{Los orígenes de la enfermedad: ¿culpa o responsabilidad social?}

La cultura científica condenaba racionalmente las densas atmósferas de culpabilidad que fomentaban las religiones cristianas, pero la culpa, esa noche dentro de sí mismo, tal vez por consustancial al hombre, tal vez porque se la usaba en pro del disciplinamiento de las conductas, a menudo renacía.

En relación a la causalidad de la enfermedad, en la segunda mitad del siglo XIX se enfrentaron la escuela del contagio con Pasteur y Koch a la cabeza, y la escuela de la hereditariedad del mal; pero ambas concluyeron por admitir que el «terreno», la predisposición a la enfermedad, era fruto, o de las condiciones sociales, o de los «vicios», llamados más tarde por la medicina «conductas personales». Pero fuesen la miseria y el hambre, o el alcohol y la trasnochada las causas de la tuberculosis, para poner un ejemplo, la culpa personal siempre concluía rondando. Sin embargo, la «moral fisiológica» apostó como causa de la enfermedad a la responsabilidad social y no a la culpa personal. La concepción de la enfermedad como producto social se impuso con facilidad en el Uruguay batllista del Novecientos. La sensibilidad de aquel movimiento político para con la miseria obrera, y la permeabilidad de la sociedad uruguaya toda a este tipo de explicación científica, denotan una de las características del Uruguay que seguramente se refieren a rasgos de su historia en la larga duración ${ }^{23}$. Pero también influyó el hecho de que el Novecientos asistió al relativamente fácil vencimiento de ciertas enfermedades infecciosas, en particular la difteria y la viruela, y no pudo combatir con el mismo éxito la tuberculosis, una dolencia más obviamente vinculada a la condición social de los que la padecían. Al reinado de la tuberculosis correspondió, en realidad, el reinado de la concepción social de la enfermedad.

Antes del Novecientos, el saber médico uruguayo había negado con frecuencia el vínculo miseria-enfermedad, aun cuando advirtiese que los que más se enfermaban eran los miserables, pero ellos también, se pensaba, eran los más «viciosos» e «ignorantes». En 1892, por ejemplo, Francisco Soca señaló en la Cámara de Diputados:

\footnotetext{
«Causa y consecuencia de la viruela bien poco tienen que ver con las condiciones sociales ambientales [...]. La viruela no elije a sus víctimas entre los desheredados de la fortuna y de la higiene, y lo mismo reina en los palacios que en las bohardillas».
}

Y si «los ricos de nuestros días» eran con menor frecuencia sus víctimas, ello solo se debía a que, dice, «más ilustrados, se vacunan más a menudo ${ }^{24}$ ».

Hasta 1925, el Consejo Nacional de Higiene apostó sobre todo por la vacunación y la desinfección como armas claves para combatir las enfermedades infecto-

\footnotetext{
23 Véase, sobre Argentina: Belmartino, Susana, y otros, (1987), Las instituciones de salud en la Argentina: desarrollo y crisis, Montevideo, Ministerio de Educación y Justicia, pp. 81 y siguientes.

24 SoCA, Francisco, (1972), Selección de discursos, Montevideo, Biblioteca Artigas, Tomo I, pp. 31-32.
} 


\section{JUAN PEDRO BARRÁN}

contagiosas, pues subyacía la opinión de que ellas eran el fruto de agentes patógenos que atacaban al cuerpo desde afuera, y de la ausencia de educación higiénica de las clases populares. Pero en 1926, la orientación del Consejo varió al ascender a la presidencia el batllista José Scosería; entonces la concepción social de la enfermedad se hizo dominante en el organismo que compartía con la Asistencia Pública el manejo de la salud colectiva en el Uruguay.

La concepción social de la enfermedad había penetrado en "la clase médica" de manos sobre todo de una dolencia, la tuberculosis. En 1905, el Primer Congreso Internacional sobre esa enfermedad ya había señalado las causas sociales como determinantes ${ }^{25}$. Dentro del cuerpo médico uruguayo fue probablemente Félix Vitale quien en 1908 promovió primero esta opinión. Este facultativo, uno de los introductores de la ideología georgista en el Uruguay de $1905^{26}$, tenía una sensibilidad muy alerta ante lo social y un singular espíritu combativo, por lo que su tesis fue presentada con agresividad: «Desinfectemos, inspeccionemos la leche y la carne [...] destruyamos los esputos, prohibamos la expectoración en público pero ese criterio es insuficiente». Y ni siquiera bastaba decir, con Robert Koch, que la verdadera causa de la tuberculosis era la miseria: «el ilustre bacteriólogo alemán [...] y todos atribuyen la tuberculosis a la miseria y sin embargo se olvidan inmediatamente para no mirar más que en el microscopio, distrayendo completamente su atención del ambiente que los rodea. [Los] higienistas regeneradores», tenían tendencia a predicar que se debía vivir «en casas salubres, de confort adecuado», culpabilizando a «los miserables por no hacerlo», como si eso se debiera a la voluntad de los pobres. El mensaje es radical, el verdadero médico debía combatir la miseria y bregar por el cambio social si quería concluir con la tuberculosis:

\footnotetext{
«El problema de la tuberculosis es un problema económico, a cuya solución todos deben contribuir. Nuestra patología social merece un estudio más profundo que el estudio de los besos y el vicio que tienen los niños en las escuelas, de chuparse los dedos. La educación de las masas es un problema que nos incumbe, pero hay que darse cuenta de lo que se entiende por educación. Educar hombres que están condenados a la miseria [...] puede ser tiempo perdido».
}

El llamado a la acción política era obvio. Tal artículo apareció, curiosamente, en la Revista Médica del Uruguay, publicación que solo incluía memorias científicas y estudios de casos clínicos ${ }^{27}$.

\footnotetext{
25 LAIGNEL-LAVASTINE y otros, (1949), Histoire Géneral de la Médecine, de la Pharmacie, de l'art dentaire et de l'art veterinaire, Paris, Albin Michel, Tomo III, pp. 216-218.

26 Cfr. BARRÁN, J.P., y NAHUM, Benjamín (1981), Batlle, los estancieros y el Imperio Británico, Tomo II: «Un diálogo difícil. 1903-1910», Montevideo, Ediciones de la Banda Oriental, pp. 89 y siguientes.

27 VITALE, Félix, (1908), «La lucha contra la Tuberculosis» Revista Médica del Uruguay, pp. 298. El ejercicio de la obstetricia en los hospitales también despertó la sensibilidad social de los médicos
} 
En 1916, el psiquiatra Santín Carlos Rossi extendió el criterio de la enfermedad como producto social a todas las dolencias, y por ello cuestionó desde el «privilegio económico» hasta el «prejuicio social»:

«El clínico para ser eficaz [debe] trabajar en la antecámara de la clínica, que es la sociedad [...]. En un cuadro de la edad adulta ve una mala infancia, en la mala infancia, un mal matrimonio, en el mal matrimonio, los defectos de la organización social. El combatiente que hay en el médico no sabe rendirse nunca: retirado el terapeuta aparece el sociólogo. Y por encadenamientos claros, lógicos, implacables, se ve conducido a incluir en la etiología de muchas enfermedades a la ignorancia, el privilegio económico y el prejuicio social».

Y como la clínica no tenía «casta ni secta», sus respuestas eran «magníficas de indiferencia o de brutalidad» y enseñaban que el médico «al lado del microscopio[tenía] lugar noble para una podadora», es decir, para la reforma social radical ${ }^{28}$. En 1915, Rossi había ya puesto ejemplos concretos de su visión del cambio económico:

«La higiene de la tuberculosis no se hace salivando sobre bicloruro, pasando paños húmedos al piso, aislando los menesteres del enfermo: se cumple dando a los organismos amenazados por el hambre y el «surmenage» un sueldo alto y un horario corto, edificando casas al sol y el aire de las afueras de una ciudad, haciendo jardines y plazas en cada barrio central ${ }^{29}$ ».

La idea de la enfermedad como producto social se extendió en «la clase médica» y tal vez informó a su mayoría; al menos los testimonios que la sostienen son más abundantes que los que, tímidamente además, señalan disensos. La realidad hospitalaria, el tratamiento de los enfermos en el interior del país, el ejercicio de ciertas

uruguayos. En 1909, Augusto Turenne sostuvo que «el trabajo sobre todo de fábricas» de las mujeres, interrumpía los embarazos o los acortaba y que «los 15 ó 20 días de vida intrauterina que los niños ricos llevan de ventaja a los pobres, son la mayor garantía de una larga vida». Creyó que «estos desastres» sólo se evitarían con «el reposo obligatorio de la obrera, ya sancionado por las legislaciones extranjeras y que esperamos ver en breve incorporado a la legislación nacional» (Turenne, A., (1909), «Asistencia obstétrica colectiva», Revista Médica del Uruguay, p. 71.). Al año siguiente, en 1910, el médico de la Liga Uruguaya contra la Tuberculosis, Sebastián B. Rodríguez, expuso el problema con criterio patriarcal y conservador: el físico de la mujer no estaba preparado «para resistir la doble tarea de atender al taller y atender al hogar», por lo cual debía «imperar el criterio de desviar a la mujer de los talleres y fábricas [para así] asegurarle un desarrollo físico más en armonía con las funciones que tiene que desempeñar en su vida y una unión y moralidad mayor en el hogar y en la familia». La opinión de Turenne era la del batllismo «progresista» y el socialismo; la de Rodríguez, similar a la de la derecha católica. (RODRíGUEZ, Sebastián B., (1910), La Tuberculosis, abril, pp. 75-78.)

28 RosSI, Santín C., (1916), «Orientaciones para la producción científica», Anales de la Facultad de Medicina, Suplemento, pp. 361-362.

29 LEGNANI, Mateo, (1915), Ensayos de higiene social, «Prólogo de Santín C. Rossi», Montevideo, Dornaleche, p. X. 


\section{JUAN PEDRO BARRÁN}

especialidades como la tisiología y la obstetricia alentaron la difusión de la tesis. Juan Pou Orfila y Mateo Legnani en 1915 y Alberto Brignole en 1916, se afiliaron claramente a esta posición. Legnani llegó a llamar a la tuberculosis y la sífilis, «modos de venganza de las clases sociales desposeídas ${ }^{30}{ }_{»}$.

En 1919, el programa de «Higiene» del profesor agregado Enrique M. Claveaux, en la Facultad de Medicina, un pionero de la medicina preventiva, ya incluía entre sus puntos, al lado del estudio del «suelo, agua, aire y climatología», el de la «habitación salubre, la higiene individual, escolar, industrial y profesional» y la llamada «higiene social ${ }^{31}$ » y cada vez más memorias científicas y presentaciones académicas de casos clínicos aludían a «la miseria crónica» en la etiología de enfermedades tan diversas como la gripe o la «trombo-flebitis puerperal», esta última, «consecuencia de una vida ruda y escasa de recursos» de un «régimen social injusto», al decir en 1919 de los médicos internos en el servicio del profesor Turenne, José M. ${ }^{a}$ Estapé y Juan A. Collazo ${ }^{32}$. La concepción social de la enfermedad llegó a las instituciones oficiales en el Novecientos de la mano del médico batllista José Scosería. Su vinculación, primero a la Comisión de Caridad y Beneficencia Pública en 1905, a la Asistencia Pública en 1910, al Consejo Nacional de Higiene en 1926 y su paso por la Liga Uruguaya contra la Tuberculosis, cambió el sentido exclusivamente «higienista» de la orientación allí vigente, sustituyéndolo por un enfoque social de la enfermedad. A los pocos días de asumir el cargo de Presidente del Consejo Nacional de Higiene, pronunció el 4 de febrero de 1926 un discurso en el seno del Consejo proclamando las nuevas normas a que debía ceñirse la institución en su lucha contra las enfermedades infecto-contagiosas, entre las que incluyó, en primer plano, a la tuberculosis:

«El hogar infectado, la habitación insalubre, la alimentación insuficiente, el exceso de trabajo y el alcoholismo, como causas higiénicas, y como causas sociales las que conducen al proletariado a la indigencia y, como síntesis de todas ellas, la miseria, son las que debilitan los medios de defensa del organismo y hacen fácil y segura la infección y el contagio. La guerra al microbio y la guerra al esputo no bastan [...] como fórmula de lucha. Hay que hacer obra de prevención, [proteger] a la madre durante el embarazo y en el parto para que no dé a luz niños débiles [...] y vigilar vivienda, alimentación, trabajo y taller [del obrero] ${ }^{33}$ ».

30 Pou OrfILA, Juan, (1915), Lógica y Pedagogías médicas, Tomo I, Montevideo, Peña, pp. 86-87 y 91-100; LEGNANI, Mateo, (1915) pp. 68-69; BRIGNOLE, A., «Defensa social contra la tuberculosis», Primer Congreso Médico Nacional, Tomo IV, Montevideo, Imp. El Siglo Ilustrado, pp. 86-89.

31 Horario y programa de los cursos, (1919), Universidad de Montevideo. Facultad de Medicina y Ramas Anexas, Montevideo, Imp. Nacional, pp. 23-24.

32 ESTAPÉ, J.M. y COLLAZO, Juan A. (1919), «Estudio de conjunto de la trombo-flebitis puerperal», Revista Médica del Uruguay, Tomo II, pp. 589-614; EIRALE, Alberto, (1919), «La gripe en Santa Rosa del Cuareim», Boletín del Consejo Nacional de Higiene, enero.

33 «El problema de la lucha contra la tuberculosis en el Consejo Nacional de Higiene», Boletín del Consejo Nacional de Higiene, febrero 1926, pp. 89-104. La fundación de la «Sociedad de Higiene y medicina Social» probablemente congregó a los médicos más identificados con la etiología social de la 


\section{BIOLOGÍA, MEDICINA Y EUGENESIA EN URUGUAY}

Pero la noción de culpa no desapareció; algunos médicos conservadores en lo social y lo político, y los sifilógrafos, jamás la olvidaron. A su vez, la mayoría de «la clase médica» transformó la culpa en responsabilidad personal por comportamientos insanos a los que ya no denominó «vicios», pero que, en los hechos, a menudo se les parecían. Los médicos Joaquín de Salterain en 1903, Sebastián B. Rodríguez en 1910, y M. Armand Ugón en 1914, señalaron que la tuberculosis y el alcoholismo no solo se combatían remediando «la escasez de alimentos», sino también terminando con «todos los excesos y vicios que debilitan el organismo», con «los placeres [que] gastaban [y] las orgías y el juego» que incluso a menudo determinaban la «vida de privaciones», según apuntó ya en plena furia moralizante el último de los nombra$\operatorname{dos}^{34}$. Pero fue la esfera de la sexualidad aquella en la que el saber médico restauró con fuerza la noción de culpa. Los médicos de la piel y enfermedades venéreas a veces la fomentaron con espectacularidad. En 1922, el folleto del Instituo Profilático de la Sífilis, titulado «Para nuestros jóvenes» alertaba sobre «males contra la familia» que traía aparejada «la culpa del marido», es decir, su contagio: «Contaminación de la mujer en el hogar», «ruina material de la familia por la enfermedad, la incapacidad o la muerte del marido», y, lo peor, «las consecuencias hereditarias, [las] hecatombes de niños muertos» o cruelmente enfermos, productos de la sífilis y la gonorrea. El ejemplo no fallaba en su objetivo, provocar miedo y culpa:

\footnotetext{
«El niño que acababa de dar a luz ha sido atacado desde su nacimiento por una espantosa oftalmía, de la que, según se dice, quedará ciego [...]. ¿Qué es esto? Una fechoría de la blenorragia producida por la madre y que, en último término, proviene de la blenorrea del padre ${ }^{35}$ »
}

La noción de «comportamiento personal» inapropiado para el mantenimiento de la salud es, en realidad, la culpa moderna, y por ello su señalamiento es históricamente clave. Los médicos comenzaron a utilizarla cuando su discurso dejó de estar completamente infiltrado por la moral tradicional -la que, a su manera, también procuraba mantener la salud-, y pasó a querer fundarse sólo en la ciencia y el culto a la salud. La «moral fisiológica» apostó a esta novedad y pretendió así secularizar la

enfermedad. Tenemos noticias de ella a raíz del Congreso Médico del Centenario, celebrado en Montevideo entre el 5 y el 12 de octubre de 1930, «La vivienda de nuestra ciudad en sus relaciones con la salud y la higiene», B.C.N.H., julio-agosto 1930, pp. 298-300.

34 SALTERAIN, Joaquín de, (1903), Conversación amistosa sobre la tuberculosis (para los obreros), Montevideo, Barreiro y Ramos; RODRÍGUEZ, Sebastián B., (1910), Cartilla sobre la tuberculosis y Nociones de Higiene Preventiva escrita expresamente para uso de escuelas y del pueblo en general, Montevideo, Imp. El Siglo Ilustrado, p.19-23; ARMAND UGÓN, L., (1914), «Memorandum del médico de Rivera, M. Armand Ugón», La Tuberculosis, enero-abril, pp. 58-59.

35 PROFESOR FourNiER, (1922), Para nuestros jóvenes, Montevideo, Peña Hermanos, ob. cit. pp. 20 y siguientes. Folleto $\mathrm{N}^{\circ} 2$ del Instituto Profiláctico de Higiene. 
noción de culpa que creyó sólo religiosa. Lo cierto, empero, es que el paciente comenzó a vivir culposamente su estilo de vida ante los reproches del saber médico.

En las tres primeras décadas del Novecientos, los médicos todavía confundían y entremezclaban la conducta impropia para la salud con el antiguo «vicio» moral. Así, en 1908, Juan Servetti Larraya, al señalar las «causas del artritismo y medios de corregirlo», al lado de «la sedentariedad física y la supraalimentación [con] alimentos demasiado fuertes [como] las carnes rojas, de caza, grandes pescados, conservas en general», colocó los excesos «de la pasión o la inteligencia ${ }^{36}{ }_{»}$. En 1930, el cancerólogo Carlos Butler, en conferencia radial sobre la profilaxis del cáncer, alertó a los oyentes contra el consumo de «verduras crudas por la posibilidad de que éstas contengan parásitos capaces de irritar el tubo digestivo», les recomendó «abstenerse del alcohol, de fumar y chicar tabaco», y también «evitar el decaimiento de la resistencia vital por el abuso de las fuerzas físicas [...] o por los vicios ${ }^{37}$ ».

La novedad ética consistió, entonces, en pasar gradualmente de indicar como causa de la enfermedad a los antiguos «vicios», a señalar como causa clave el «comportamiento personal». Siempre el sujeto era culpabilizado por no responder a las exigencias de la moral, pero ésta había variado sus contenidos: el Novecientos agregó a las tradicionales irregularidades de las cuales el sujeto debía acusarse —el peligroso coito fuera del matrimonio y la masturbación, por ejemplo-, otras nuevas, las que precisamente indicaba la ciencia como pecados contra el cuerpo y la vida larga, fallas de la inhibición ante la inmediatez del placer: la sedentariedad excesiva y la alimentación inadecuada, por ejemplo. El lazo de la sedentariedad excesiva con la vieja haraganería y de la alimentación inadecuada con la gula, revela nexos inesperados entre los saberes religioso y científico. Acciones como beber alcohol, participan de la condena de ambos saberes y cuesta, en realidad, distinguir cuál de ellos los estigmatizó más. No fumar, en cambio, parece un consejo higiénico en estado de pureza, pero la culpa por desconocerlo recuerda las viejas sanciones. Debemos advertir que la evolución tendía a reducir y no a incrementar la lista de los pecados. En los hechos, la moral derivada del cuidado obsesivo de la salud condujo a un acotamiento del mal al terreno casi exclusivo de lo que perjudicaba la vida larga. Pero en el Novecientos esto no se percibe aún con nitidez.

Señalemos, por último, que la insistencia del saber médico en la responsabilidad personal del enfermo en la etiología de su dolencia, tuvo dos efectos: en primer lugar, hizo que el sujeto retomase el control de su salud, hecho que la medicina social en parte impedía al insistir en la etiología colectiva de la enfermedad; en segundo lugar, contribuyó a disculpar a la sociedad de su responsabilidad en la producción de la

\footnotetext{
36 SERVETti LARRAYA, Juan, (1908), «Consideraciones generales sobre el artritismo», Revista Médica del Uruguay, pp. 7-20.

37 BUTLER, Carlos, (1930), «Conferencia», Boletín del Consejo Nacional de Higiene, noviembrediciembre.
} 
enfermedad. Desde este ángulo puede ser considerada esa insistencia en la conducta personal como un retorno político a un saber más conservador del orden social.

\subsection{El hombre fisiológico.}

Santín Carlos Rossi en su libro ya citado, El Criterio Fisiológico, dio cuenta acabada de la utopía moral de «la clase médica» y del nuevo culto a la salud del cual derivarían y al cual se referirían los nuevos valores. Esa ética, sobre la que volveremos, implicaba severos deberes con uno mismo y los demás en pro de la preservación de la salud personal y la social que estaban rigurosamente entrelazadas; y permitía sólo el placer legitimado por «el Amor y la madurez emocional», dos requerimientos que en realidad lo controlaban - dejaban fuera del ejercicio del placer al adolescente, por ejemplo-, casi tan rigurosamente como la vieja moral cristiana. El hombre ideal no era el superhombre nietzscheano, rechazado por «cruel y amoral», ni el estoico que «sufría resignadamente»; ambos modelos eran «incompletos» desde el punto de vista «fisiológico». El nuevo hombre, que estaba ya en germen en el común, desterraría el dolor y ejercería todas sus funciones vitales, viviría «la castidad sin nostalgia, el sensualismo sin vicio y el amor ingenuo dulcemente perturbador». Todas «las fuerzas ciegas de la Naturaleza [serían así] interrogadas por la Inteligencia, conquistadas por la Fuerza y comentadas por el Sentimiento del Hombre ${ }^{38}$ ».

Este superhombre batllista -Santín Carlos Rossi lo era y en el batllismo se hallan elementos de esta utopía - encarnaría todas las virtudes del culto a la salud y recuperaría el orden y la armonía en base al respeto del placer, limitado por el respeto del propio cuerpo y de la «raza». El «Amor» liberado de las convenciones burguesas -noviazgo eterno y matrimonio indisoluble-, sería el único factor legitimador de la cópula. Pero en la erradicación absoluta del dolor y en ese placer medido, ya estaba implícito el espíritu discreto y condenador de todos los excesos, típico de una sociedad de clases medias. Por eso en 1938, casi veinte años después de haber aparecido el libro de Santín Carlos Rossi, la revista Vivir acotó y empequeñeció el mensaje al hedonista: «¡Sufrir poco! ¡Vivir mucho!». Para no volverse «arterioesclerótico» había que: «a) abstenerse de alcohol [...]; b) alimentación correcta, a base de verduras y frutas, simple, con tranquilidad espiritual; c) enfoque de la vida por su lado sonriente; luchar sí, pero sin caer en abusos; educar la voluntad para hacer imposible el pesimismo y el esplín ${ }^{39}$ ». La sociedad ya no le pedía otra cosa a la medicina que la vida larga, y la medicina la prometía de seguirse ciertas conductas: la moralización de la medicina había culminado en la medicalización de la moral.

38 Rossi, S.C. (s.f.) El Criterio Fisiológico, pp. 292-295.

39 R. V. (1938), ;Sufrir poco! ¡Vivir mucho!, junio. 


\section{LA SOCIEDAD BIOLÓGICA Y SUS UTOPÍAS: SOLIDARISMO Y EUGENESIA.}

\subsection{El saber médico propone la reforma social}

La moral y la concepción de la enfermedad como producto social anteriormente expuestas, condujeron a que la mayoría de los médicos que han dejado testimonios escritos, bregase por una sociedad ideal que expulsaría la enfermedad, entronizaría la salud - que era la felicidad-y fundaría un nuevo orden social sobre bases estrictamente «biológicas».

Esa mayoría bregó por la reforma social. En 1915, Santín C. Rossi fue terminante: las «conclusiones de la Higiene son desfavorables a la actual organización social ${ }^{40}$ ». Ese año también, Mateo Legnani ironizó sobre las colectas del «día de los tuberculosos» organizadas por la Liga Uruguaya contra la Tuberculosis, a cargo de «aristocráticas y delgadas niñas»; es preciso «que no fuesen delgadas y aristocráticas, que el dinero deje de ser rey [...] y la Razón domine. Es menester que no haya injustamente pobres y ricos, que no se vean hambres y orgías[...] que la sociedad se arregle ${ }^{41}$ ».

El programa de cambios sociales era vasto y comenzaba con la sustitución de la vivienda popular. De juzgar el volumen de lo escrito y la jerarquía de las instituciones médicas implicadas en ese pronunciamiento, la primera reforma debía consistir en sustituir los tugurios que habitaban los sectores populares rurales y urbanos, el rancho y el conventillo, por barrios jardines o habitaciones higiénicas y no sobrepobladas a construirse por el Estado o la Municipalidad, y en las que se cobrarían alquileres baratos. «La casa independiente [para] cada familia» era el ideal dominante en ese plano; el modelo urbano más de una vez citado fue el «grupo de casas en el Reducto (Montevideo)» que había edificado el filántropo católico Alejo Rossell y Rius. Erasmo Arrate, Alberto Brignole y Francisco Soca llegaron a sostener que el rancho y el conventillo debían ser «destruídos» aún a costa de la «expropiación [de] los propietarios fastuosos» sobre cuyas tierras estaban; claro que «esas leyes no vendrán, no pueden venir, sino después de estudios graves». La opinión médica fue tan unánime en relación a esta necesidad de modificar la vivienda popular, que el Primer Congreso Médico Nacional de 1916 votó esa conclusión, al menos en el caso de los «obreros» ${ }^{42}$.

La mayoría también luchó por cambios que alteraban un tanto más profundamente el orden social y económico vigente: «la reglamentación del trabajo e higieni-

\footnotetext{
40 LegnAni, Mateo, (1915), Ensayos de Higiene Social, «Prólogo» de Santín C. Rossi, p. IX.

41 LEGNANI, Mateo, (1915), p. 61.

42 «Discurso del Presidente del Congreso», (1917), Primer Congreso Médico Nacional, Tomo I, p. 55; «Quinto voto aprobado», PCMN, Tomo II, p. 873; «Profilaxis de la tuberculosis en Uruguay», PCMN, Tomo IV, pp. 75-76. RoDRíGUEZ, Sebastián B., «Cartilla sobre la tuberculosis [...], ob. cit. p. 42. SOCA, Francisco, «Selección de discursos», ob. cit. Tomo III, pp. 210-220.
} 
zación de los locales en que se efectúa», el fomento «del cooperativismo y los medios de abaratar las subsistencias», «el mejoramiento de los salarios», «los seguros contra la desocupación, la enfermedad y la invalidez» y «la fundación de colonias agrícolas industriales», fueron, por ejemplo, reformas indicadas por el Consejo Nacional de Higiene en septiembre de 1925 al Consejo Nacional de Administración ${ }^{43}$.

La protección a la mujer trabajadora fuera de su hogar, concilió las tendencias patriarcalistas de aquella «clase médica» con su afán reformista. El obstetra Augusto Turenne apoyó desde principios del Novecientos «la limitación de las horas de trabajo, la supresión del trabajo nocturno, el alejamiento de la mujer de ciertas industrias insalubres, el reposo semanal», tanto en pro de la salud de la mujer como del amamantamiento y la crianza de sus hijos. A estos efectos, «el reposo obligatorio» antes y después del parto fue la idea mejor recibida; el Cuerpo Médico Escolar incluso obtuvo de la Dirección General de Instrucción Pública que las maestras embarazadas gozasen de «licencia de un mes antes del parto y un mes después de él», disposición ya vigente en $1910^{44}$.

El combate contra la prostitución también concitó la búsqueda de cambios y hábitos sociales. Miguel Becerro de Bengoa en 1919 y Héctor del Campo en 1923, bregaron por el «aumento de los sueldos [y] la fijación del salario mínimo» de las obreras, $\mathrm{y}$ «el aumento de puestos» para las mujeres en general, facilitándose, por ejemplo «su ingreso a las carreras liberales». Sin embargo, Héctor del Campo estimó que la miseria no era «la causa directa de la prostitución», sino la indirecta, primero, por obligar «a vivir a padres e hijos en una promiscuidad que hace imposible respetar todo sentimiento de pudor», y segundo, porque «las tareas del obrero lo absorben por completo [y] descuida así la vigilancia de sus hijas». En su caso, se dieron la mano la reforma social y el conservadurismo moral ${ }^{45}$.

La reforma social preconizada por esta mayoría médica a veces alcanzó tonos radicales. En 1915, Mateo Legnani observó que «la gran higiene» llevaba «a preconizar reformas [...] tan profundas que asustan[...] con solo imaginarlas se experimenta

\footnotetext{
43 «Nota de Julio Etchepare», (1925), Boletín del Consejo Nacional de Higiene, septiembre, pp. 646-657.

44 LAMAS, Alejandro, (1911), Maternología, Montevideo, Barreiro y Ramos, pp. 297-299 y 302. Cita de A. Turenne; TURENNE, A., (1916), «El trabajo de la mujer embarazada», Revista Médica del Uruguay, pp. 151-153.

45 BeCERro De BengoA, M. (1919), Higiene social, Montevideo, C.N.H., El Siglo Ilustrado, pp. 47-49. B.C.N.H. febrero 1923, CAMPO, Héctor del, art. cit. pp. 135-137 y 181-200. Lo cierto es que no toda la "clase médica» tuvo esta visión social de las causas de la prostitución. En 1914, el médico Pedro Sanguinet opinó que «Las menores arrastradas al vicio» en el departamento de Soriano, donde residía, lo habían sido «por propia inclinación» o «por negligencia de los padres evidenciada en la absoluta libertad que les conceden, sustrayéndolas de la Escuela y de ocupaciones honestas»: B.C.N. agosto 1914, p. 361: Informe anual de Pedro Sanguinet.
} 


\section{JUAN PEDRO BARRÁN}

una inercia muy semejante a la del pánico ${ }^{46} \gg$. Es que el año anterior, en 1914, su colega y correligionario político, el médico batllista José Scosería, había llegado a sostener que, por ejemplo, «la lucha antituberculosa [...] es una lucha social [...], un conflicto entre el interés general e intereses particulares: es la lucha de los obreros contra el patrón exigiendo menos horas de trabajo, más higiene en el taller y mejor salario [...] de una parte de la nación mal nutrida, mal alojada, miserable, contra otra parte del país más feliz: la lucha de los que nada tienen y nada pueden contra los que todo lo tienen y todo lo pueden, la eterna rebelión de los esclavos contra los amos ${ }^{47}$ ».

Pero estos «radicalismos» no deben llevarnos a confusión. La mayoría de la «clase médica», incluso estos dos exponentes extremos que terminamos de citar, fue reformista y no revolucionaria. Ese mismo año de 1914, José Scosería llegó a conceder, a un maestro conservador postulante de la «holgazanería» como causa fundamental de «la tuberculosis [y] la miseria» reinantes en el interior del país, que ese vicio moral ocasionaba, sin duda, «la miseria [...] la mayor parte de las veces [pero que] no se llega por eso solo, se llega por los defectos de las condiciones sociales, por causas individuales, por causas de orden social y por muchas otras $\operatorname{cosas}^{48}$ ».

Los cambios apoyados por la mayoría de la «clase médica», si bien afectaban los intereses del orden conservador vigente en ese Novecientos uruguayo, no alteraban su esencia; por ejemplo, esa mayoría nunca mencionó el término confiscación sino expropiación, propuso la elevación de los salarios pero no la supresión de la relación salarial, y bregó por el fin de la prostitución pero no por la libertad sexual. Las críticas al orden establecido y los «excesos» de la burguesía, se conciliaron con la justificación de algunos de sus rasgos claves; por ejemplo, el mérito y el esfuerzo personales como causas de la desigualdad social, legítima, principio que la mayoría de la «clase médica» defendió más de una vez. Ciertas posturas parecían más radicales todavía sólo porque se contextualizaban en el medio a menudo ultraconservador del patronato uruguayo. En realidad, esta mayoría de la «clase médica» era de un «progresismo» obviamente afín al batllista, por defender la acción interventora del Estado en pro de la salvación iluminista de las masas y «culpabilizarlas» en alguna medida de los vicios -alcoholismo y «haraganería»-que las degeneraban.

En efecto, la compulsa documental revela que la mayoría de los escritos de la «clase médica» uruguaya del Novecientos, tiene posiciones ideológicas y políticas afines con el «progresismo» social que dominaba en el socialismo y el batllismo, y aun se insinuaba en las alas radicales del partido Nacional y la Unión Cívica. Los lazos con el batllismo son notorios en varios casos de los autores médicos analizados. No sabemos cúantos médicos eran batllistas, pero sí que lo fue, en momentos claves

\footnotetext{
46 LEGNANI, Mateo (1915), p. 28.

47 SCOSERÍA, José, (1914), «Exposición», La Tuberculosis, enero-abril, p. 22.

48 «Conferencia encargada de orientar la lucha contra la Tuberculosis en campaña», La Tuberculosis, enero-abril 1914, pp. 127-128.
} 


\section{BIOLOGÍA, MEDICINA Y EUGENESIA EN URUGUAY}

de su vida pública, un importante porcentaje de los citados en este artículo: Francisco Soca, Atilio Narancio, José Scosería, Augusto Turenne, Mateo Legnani, Santín Carlos Rossi, Félix Vitale y Américo Ricaldoni. Para ilustrar con un solo ejemplo, Roberto B. Giúdice, el médico director y redactor de la revista Vivir entre 1937 y 1949, la primera que la «clase» publicó para divulgar sus nociones de medicina preventiva, además de periodista del periódico El Día, fue coautor del estudio hagiográfico más importante sobre el batllismo que existió hasta no hace muchos años, titulado Batlle y el batllismo ${ }^{49}$. Sí conocemos el peso de la «clase médica» entre los dirigentes más conspicuos de ese movimiento político. De los 77 nombres que en otra obra estudiamos como integrantes de su dirección entre 1903 y 1933, el 77\% eran profesionales universitarios; de ellos, el $71 \%$ eran abogados y les seguían, lo que sí era novedoso en un partido político uruguayo del Novecientos, un 14\% de médicos y un $10 \%$ de ingenieros ${ }^{50}$. Es más, los escritos citados anteriormente de estos médicos solo adquieren todo su significado, bastante más rebelde y cuestionador de lo que indicaría un análisis meramente conceptual, dentro del contexto político-social en que fueron dichos o publicados, en plena ofensiva del batllismo por la imposición de sus postulados reformistas más resistidos por las «clases conservadoras». Alberto Brignole, el tisiólogo, y Augusto Turenne, el obstetra, por ejemplo, apoyaron con calidez la limitación de la jornada de trabajo a 8 horas en 1916, año en que precisamente la legislación la impuso - la ley de 17 de noviembre de 1915 entró en vigencia el 17 de febrero de 1916 - en medio de una fuerte oposición patronal e importantes huelgas obreras $^{51}$. Los elogios de Augusto Turenne en 1915 al «socialismo de buena ley» que aprendía en los hospitales al contacto con la miseria ${ }^{52}$, el apoyo irrestricto de Santín C. Rossi en 1914 a «las aspiraciones del socialismo de estado» en cuyo cumplimiento creía poder encontrar las condiciones sociales que garantizarían la salud mental ${ }^{53}$, la esperanza de Mateo Legnani en 1917 en «los ensueños o las ficciones de los socialistas» para poner freno a las enfermedades, esperanzas que creía se podían concretar de manera más realista a través del «Partido Colorado, el batllista», todo ello indica una identificación precisa de miembros importantes de la «clase médica» con el batllismo radical ${ }^{54}$.

49 GonZÁlez ConZI, E. y GiÚdice, Roberto B., (1959) Batlle y el batllismo, Montevideo, Medina, p. 411, 2da. edición.

50 Cfr. BARRÁN, José Pedro y NAHUM, Benjamín, (1982), Batlle, los estancieros y el Imperio Británico, Tomo III, El nacimiento del batllismo, Montevideo, Ediciones de la Banda Oriental, pp. 101 en adelante.

51 Brignole, A. (1917), «Defensa social contra la tuberculosis», Primer Congreso Médico Nacional, Tomo IV, pp. 101-120

52 TURENNE, A., (1915), «Lección inaugural», Revista Médica del Uruguay, Tomo I, p. 415.

53 Rossi, Santín C., (1914), El alienado y la sociedad, Montevideo, Tip. Administración de Loterías, pp. 47-48.

54 LEGNANI, Mateo, (1917), Catecismo de higiene, p. 13; Ibid. (1922), p. 11. 
En 1918, a un año de la Revolución rusa de 1917, Augusto Turenne se afilió a algunos postulados del derrotado batllismo radical y hasta avizoró la solución de la «comunización filial» para el problema del abandono y la mala educación de los niños por sus padres: «El Uruguay, cuya orientación hacia indefinidos progresos culturales y sociales le convierte, con alarma de muchos, en campo de experimentación sociológica, para consuelo de los que profesamos ideas avanzadas [...] se ha preocupado de incorporar a sus costumbres y su legislación preceptos que estan llamados a moderar [...] el abandono del niño. ¿Será la comunización de los hijos un remedio a ese abandono? Las audaces realizaciones del maximalismo ruso obligan al sociólogo a detener sus miradas sobre el sangriento alambique [...] en que pugna por elaborarse una nueva forma social de la que tal vez sea el mayor enemigo la incultura y la mentalidad primitiva de los elementos en quienes se ha ensayado». Pero en el Uruguay, donde los «elementos» eran diferentes, tal vez podía ensayarse «una clarividente protección [de los niños] que realizará científicamente [su crianza] para sustituir la errónea formación física, mental y moral que fluye de una incompleta y descarrilada concepción de los deberes paternales». El Estado guiado por los científicos criaría y educaría a los niños y aceptaría, eso sí, «las inevitables pero no irritantes desigualdades que la capacidad física, la preparación mental y la energía volitiva [harían] renacer cuantas veces un ingenuo [comunismo] pretenda crear organizaciones estrictamente igualitarias ${ }^{55}$ ». Este punto de vista de Turenne coincidía de manera rigurosa con algunas de las utopías del batllismo radical y con su fe en la conducción y modelación de la sociedad por un Estado iluminado por la ciencia y sus sabios. A la vez, en cambio, radical sin dudas, debía garantizar la desigualdad y la libre competencia, motores de la sociedad burguesa, por cuanto la desigualdad era postulada como un elemento consustancial de la condición humana.

El apoyo de buena parte de esta «clase médica» a proyectos económicos y sociales concretos del batllismo testimonia otra vez los lazos que estamos describiendo. En 1916, Augusto Turenne señaló la necesidad, para proteger la salud de los sectores populares, de «distribuir mejor las cargas sociales [y establecer] contribuciones gradualmente progresivas a las sucesiones ${ }^{56} »$; el mismo año, Fernando Giribaldo apoyó el proyecto del diputado batllista Eugenio Martínez Thedy, que obligaba a los propietarios o arrendatarios de campos a proporcionar «alojamiento cómodo y de capacidad suficiente al personal de trabajo ${ }^{57}$ » y Mateo Legnani en 1915 opinaba que «los médicos deben enrolarse en las filas del partido del impuesto único», porque esa era

55 TURENNE, A, (1918), «Profilaxis del abandono del niño», Revista Médica del Uruguay, Tomo I, p. 475.

56 TURENNE, A., (1917), «Medios de lucha contra el aborto criminal provocado en nuestro país», Primer Congreso Médico Nacional, Tomo III, pp. 306-307:

57 GIRIBALDI, Fernando, (1917), «Higiene del habitante de nuestra campaña», Primer Congreso Médico Nacional, Tomo IV, pp. 23-24. 
la mejor forma de «luchar por la salud», es decir, que solo el georgismo -el impuesto único sería sobre la tierra y expropiaría su valor-concluiría con el latifundio y la miseria ${ }^{58}$, opinión que se volvió reiterativa en la revista Vivir dirigida por el médico Roberto B. Giúdice y en cuyo consejo patrocinador figuran algunos de los más destacados integrantes de la «clase médica» de esos años ${ }^{59}$.

Es probable que el tipo de documentación manejada —el escrito médico de tipo sociológico, en este caso -haya sobredimensionado la relación entre la «clase médica» y la aspiración a la reforma social. Pero lo que sí parece indiscutible es que el saber médico quiso extraer consecuencias políticas de sus postulados biológicos y ellas lo llevaron a plantear una sociedad ideal que no pudo librarse por entero de la influencia de los contextos ideológicos de su época.

En 1919, Santín C. Rossi planteó en su libro El Criterio Fisiológico, ya parcialmente comentado, la utopía social del saber médico precisamente enmarcada por el solidarismo batllista, y que resultó ser, en realidad, una peculiar fundamentación biológico-cientifista de él. La biología era la que exigía, tanto la vida en sociedad, como el rasgo clave de su organización: la «solidaridad». Tierra, aire, luz, «materiales nutritivos», vivienda, vestido, cultura, seguridad, todas esas y otras similares necesidades, el hombre solo podía satisfacerlas mediante la «asociación», que, en última instancia, le garantizaba «la defensa y conservación de la especie». Esa «asociación» descansaba en un «egoismo bien entendido» que aconsejaba «la solidaridad social del hombre»; sólo esa imprescindible «cooperación», «humanizaba» al hombre, le aseguraba mediante la educación y el trabajo el dominio sobre la naturaleza. Los «deberes y derechos» de cada uno eran meras «traducciones verbales de funciones biológicas», por ejemplo, «la humanización de las funciones reproductoras exige al hombre la protección de los hijos durante el período de crecimiento [...] y [de] la persona del sexo femenino que haya elegido como pareja, durante el tiempo en que la fisiología de la maternidad no le permita trabajar».

Era la preservación de la especie la que determinaba la existencia de los únicos «privilegiados nutritivos» que podían vivir sin trabajar: niños, mujeres embarazadas y ancianos; y la que imponía la igualdad del esfuerzo al resto, de lo que se deducía que el privilegio social y las clases ricas y ociosas estaban condenados por la biología pues «usurpaban un lote ajeno de energías».

58 LEGNANI, Mateo (1915), p. 48. Id. id. : «Esbozo de una higiene integral», ob. cit. p. 19.

59 «El impuesto de la tierra» Vivir, Editorial, enero 1942. Otros médicos adoptaron posiciones políticas más contestatarias. Paulina Luisi, por ejemplo, fue socialista, y probablemente a ella se debiera que la plataforma electoral de ese partido, en 1918, incluyera puntos tales como «la reglamentación de las condiciones de salubridad en que se encuentran las viviendas que se entregaban al pueblo» y «el establecimiento de los sistemas de represión del alcoholismo sobre la base de la voluntad popular»; LuISI, Paulina, (1919), Para una mejor descendencia, Buenos Aires, Perrotti, pp. 28-29. 


\section{JUAN PEDRO BARRÁN}

«La igualdad [era] un factor biológico» a mantener por la sociedad, pero los «méritos» personales podían alterar la uniformidad, pues de ellos se deducía la legitimidad «fisiológica» de un trato diferente a cada uno de acuerdo con su esfuerzo y su capacidad.

El gobierno debía regirse por leyes «que se asemejan a las científicas en que indican lo que hay que hacer si se quiere seguir viviendo bien». Y si la sociedad estaba organizada de acuerdo con los principios precedentes, el Estado podría desaparecer: «su supresión es perfectamente concebible en una sociedad de hombres completos, es decir, lo suficientemente educados para cumplir por ellos mismos sus deberes y limitar sus derechos sin la coerción de la ley». El problema radicaba en que «la sociedad actual» no estaba organizada solo de acuerdo con estos principios «fisiológicos»: en ella reinaban el desequilibrio social, el dolor, la enfermedad y la ignorancia. «El dolor [por ejemplo] era una advertencia orgánica de que no se cumple la condición de equilibrio de la vida», su existencia social comprobaba el desequilibrio de la vida en lo colectivo, tarea que la biología imponía remediar. Los hombres tenían derecho «biológico» en defensa de su especie, a restablecer el equilibrio y eliminar los males con el apoyo del estado benefactor de los débiles, desocupados y miserables, y educador científico de los ignorantes. Todos estos, en realidad, eran actos de egoísmo defensivo de la especie que pretendían anular las consecuencias patológicas de la organización social defectuosa. Sólo la sociedad organizada en base al respeto de los principios «fisiológicos» vería desaparecer «el privilegio nutritivo, la esclavitud económica de la mujer y la libertad que actualmente tiene el hombre para dañar, única libertad individual que limitaría la organización fisiológica». Abolir «el privilegio nutritivo» significaba concluir con «la toma de energías del ambiente» sin el correspondiente esfuerzo personal, por lo que debían eliminar «la herencia, la propiedad de renta o el simple numerario que no represente remuneración de esfuerzo personal». Ese «privilegio», además, era dañino tanto para los que lo debían sostener a costa de su propio esfuerzo, como para los que lo usufructuaban. Lo que sigue ejemplifica con claridad el tipo de razonamiento de Santín C. Rossi, su curiosa alianza de argumentos biológicos y políticos, esa afanosa búsqueda de los fundamentos científicos de una sociedad ideal que tanto se parecía al proyecto del batllismo radical: «Imaginemos la jornada biológica de un rico heredero. Supongamos que se educa en condiciones fisiológicas, para ser un hombre completo y no mutilar la vida. La ley del óptimo nutritivo (comer lo suficiente para vivir, y no más), lo obligará a la sobriedad nutritiva, en calidad y cantidad [...] lo obligará a ejercitar su sistema neuro-muscular, si no en una dirección útil (trabajo ), por lo menos en una agradable (deporte); la educación cortical le hará buscar la emoción favorita —estética, educadora, científicacuya resonancia es social y no individual. En cualquiera de esos casos, el privilegiado no necesita su privilegio y tendría su puesto distinguido en una sociedad armónica. Si en cambio el heredero es ignorante, disipador, voluptuoso, buscará siempre emociones raras [o] se intoxicará [...] ese sujeto perjudicará su propio organismo». 
De lo cual Rossi deducía que «el privilegio no llena por él mismo ninguna exigencia orgánica y en cambio obliga a otros individuos a mutilar su organismo». La abolición del privilegio llevaría a la desaparición «de todas las instituciones que lo sostienen: ejércitos, tribunales, cárceles y otros mecanismos administrativos». El resultado final de la sociedad reformada siguiendo «el criterio fisiológico», sería la abolición del privilegio, la miseria, la ignorancia y «la nostalgia» del placer, padres de la desigualdad, el delito, la enfermedad el dolor y el vicio ${ }^{60}$.

En 1919 también, Rossi tradujo esta utopía médico-batllista al terreno de las realidades sociales uruguayas y la convirtió en un elogio de «la clase media», la única que podía garantizar la formación de «una mentalidad de hombre normal, fisiológico». Al inquirir sobre la influencia de «las condiciones económicas del hogar en la salud y mentalidad de los niños" halló que "el chico que se cría en la miseria tiene una mentalidad miserable: irritado, envidioso, simulador o rebelde, vengativo, lógicamente vengativo. El chico que se cría en la abundancia —en cambio-podrá ser generoso, noble, expansivo, si tiene la suerte de encontrar en el hogar, a pesar de la abundancia, aquellos ejemplos en sus padres [...] pero está expuesto al extremo opuesto de la mentalidad miserable: la vanidad, el orgullo de clase». El que estaba mejor situado «para formarse una mentalidad de hombre normal, fisiológico, es el niño de la clase media [...] por eso el porvenir de la raza [humana] exige la profilaxis de la miseria y de la superabundancia ${ }^{61}{ }$.

De este modo, la utopía médica que pretendía matar el dolor y terminar con el privilegio, concluía, un tanto pedestre y hedonísticamente, en el elogio de las virtudes mentales de la clase media. El saber médico volvía así a sus específicos orígenes humanos y reivindicaba de este modo el recuerdo de tantos inmigrantes que habían sacrificado sus «cuerpos fisiológicos» por el doctorado de sus hijos.

2.2. El saber médico propone la purificación de la raza humana: la eugenesia y su contexto.

La eugenesia, teoría que propugnaba combatir la «degeneración» de la «raza» amenazada por las enfermedades y los «vicios» populares, en particular, alcoholismo, sífilis, tuberculosis y dolencias mentales, fue la creencia dominante entre los médicos del Novecientos y dio forma concreta a la utopía de una sociedad gobernada por principios extraídos de la biología. Esos principios se sintetizaron en la preservación de la «calidad» de la «raza», por lo que concluyeron condenando lo anormal, lo criminal, lo marginal y lo enfermo, en perfecto acuerdo con el orden establecido, aunque con una dureza

\footnotetext{
60 Rossi, Santín C., (s.f.), El Criterio Fisiológico, Véase el Capítulo X en adelante, p. 226.

61 Rossi, Santín C., (1919), «La salud y mentalidad de los niños en relación con las condiciones económicas del hogar», Revista Médica del Uruguay, Tomo II, pp. 519-522.
} 
y frialdad científica que solo lograron imitar -y superar-los regímenes nazi-fascistas europeos nacidos, precisamente, en los años veinte y treinta de este siglo, cuando la eugenesia había conquistado un lugar preeminente dento de las creencias del saber médico. El vínculo entre reforma social y eugenesia, sobre lo que volveremos, dio un sello peculiar al eugenismo uruguayo pero no pudo evitar su ambigüedad política. En realidad, lo que ligaba a la sociedad ideal de Santín C. Rossi con el eugenismo, era la convicción de los médicos de que su saber tenía el derecho y la obligación de regular la vida humana y modelar tanto el cuerpo del hombre como la vida de la especie humana. Las ideas claves que compartían ambas utopías eran la salvación de las masas y/o de la «raza» por los científicos iluminados, y la creación de una nueva moral basada en esos objetivos a lo que todo debía subordinarse. Pero las dos utopías no representaban los mismos intereses sociales, y eso infiltró sus principios. La salvación de las masas implica la defensa de los débiles y los miserables; la eugenesia conducía, en cambio, como se verá, a la esterilización de los débiles y los enfermos. A pesar de esta evidente contradicción, el saber médico del Novecientos logró que ambas ideas cohabitaran en su interior, tanto las unía la creencia común en la omnipotencia de la medicina.

La idea de la degeneración de la «raza» implicaba casi siempre el principio de la transmisión hereditaria de los caracteres patológicos adquiridos, y fue expuesta por vez primera por el médico francés B.A. Morel en 1857, atemorizado por el espectáculo de la degeneración física y «moral» del proletariado de su país. La previsión de un fin catastrófico de la «raza» se dio paradógicamente la mano con su opuesta, la utopía de un perfeccionamiento físico, moral e intelectual indefinido del hombre que la medicina venía acariciando desde fines del siglo XVIII con Condorcet. Ambas convicciones partían de la misma base: la especie humana y la «raza» se construían con el esfuerzo de las generaciones sucesivas pero también podían destruirse o degenerarse por efecto de las enfermedades que atacaban esa cadena de la que la generación presente era sólo un eslabón.

Los médicos del Novecientos creyeron todos en que la preservación de las virtudes y la salud de la «raza» era la tarea clave de su ciencia y que a ella debían subordinar su acción los gobiernos. A veces, en los «progresistas», el concepto de «raza» virtualmente se identifica con toda la especie humana, pero otras veces, la percepción que el saber médico tuvo de la «raza» fue referida solo a la de la nación -a veces, el continente- de origen de los facultativos. En 1928, lo expresó Eduardo Bastos en el seno del Consejo Nacional de Higiene: «no solo junto al lecho del enfermo, aliviando dolores [...] es como se cumple la misión del médico moderno, sino que es también un alto deber convencer al hombre sano que debe mantenerse tal y ser así un eslabón útil en esa cadena de solidaridad social que permite el avance de la civilización ${ }^{62}$ ». En 1920, un no médico, Manuel Medina Betancourt, ex-secretario de José Batlle y

62 BASTOS, Eduardo, (1928), «Discurso del doctor Eduardo Bastos», Boletín del Consejo Nacional de Higiene, mayo, p. 184. 
Ordoñez y propulsor del control de los casamientos para evitar que los enfermos pudiesen procrear, resumió el principio clave de la utopía médica sobre el futuro de la, en este caso, especie humana: «Las presentes generaciones han transformado el estrecho individualismo que heredaron, en un colectivismo amplio y generoso, solidario con la vida [...] y con las generaciones futuras. [Las nuevas generaciones] saben que son un puente y no un punto, eslabones de una cadena infinita y no cuerpos errantes ${ }^{63}$ ». Evitar la «degeneración»-de la especie, de la raza- y en su lugar contribuir mediante el saber científico a construir un cuerpo humano saludable, vigoroso e inteligente, eran tareas posibles que correspondían a la medicina y los gobiernos.

La atmósfera culpable que la creencia cristiana en el pecado original había generado en Europa desde la Edad Media, revivió a la manera cientificista del siglo XIX, cuando el saber médico comenzó a defender la idea de que el mal -la enfermedadera hereditario. El médico español Pedro F. Monlau, en 1865, expresó con claridad el temor a la degeneración, tanto de la «especie humana» como de la célula social que le interesaba como católico y burgués: la familia: «A los ojos de la higiene, la predisposición a enfermedades análogas es una incompatibilidad grave, un impedimento fisiológico para el matrimonio. Un predispuesto a las escrófulas y una predispuesta a la tisis darán origen a una familia desventurada». Las conclusiones finales eran terminantes: «Una legislación sensata y previsora debería poner en consideración esos hechos, y sobre todo poner el debido remedio pero por desgracia nuestros códigos nada estatuyen en favor de la regeneración física de la especie humana. Los gérmenes de la sífilis, la tisis y del cáncer, de la gota y el herpes, de la fealdad y la disminución de la talla, de la locura y de la epilepsia, podrían irse ahogando y extinguiendo en menos de un siglo, sin más que quererlo», es decir, prohibiendo el casamiento de los que tuvieran esas dolencias ${ }^{64}$.

La idea de controlar la «raza» y vigilar sus apareamientos para mejorarla e impedir la «degeneración», provenía, naturalmente, de las manipulaciones que la revolución agrícola inglesa venía realizando desde el siglo XIX con razas animales. La Liga Argentina de Profilaxis Social lo recordó al pedir al Congreso de su país el establecimiento del certificado de salud para celebrar matrimonios, y lo hizo con un razonamiento que al Consejo Nacional de Higiene uruguayo le pareció tan oportuno que lo trancribió en 1921: «Reflexiónese que las razas animales son motivo de especiales requisitos para garantizar su salud y su procreación. ¿No habría llegado acaso el momento de aplicar iguales medidas a la raza humana? Los ganaderos exigen con mucho interés el pedigree de sus animales reproductores, pero nada o muy poco se ha

\footnotetext{
63 Medina Betancourt, Manuel (1920) «El amor en los débiles y enfermos», La Razón, (diario de Montevideo), 25 octubre, p. 1 , cols. 5 y 6 ; p. 2 , col. 1.

64 MonlaU, Pedro F. (1865), Higiene del matrimonio o el libro de los casados, París, Garnier, pp. 515-517.
} 
hecho entre nosotros para premiar los mejores ejemplares de la raza humana ${ }^{65}{ }_{\eta}$. Correspondió al inglés Francis Galton (1822-1911), primo de Charles Darwin, impulsar la idea de eugenesia en el mundo a partir de 1883. La definió como la ciencia que procuraría que cada especie, clase o raza, llegase al máximo de sus posibilidades mediante el cruzamiento entre los mejores y la esterilización de los seres biológica y mentalmente defectuosos. Su teoría descansaba sobre dos supuestos, la selección natural dawiniana y la herencia de los caracteres adquiridos.

Parte de la «clase médica» occidental, sociólogos, biólogos y estadistas, fundaron con estas ideas el movimiento eugenista que se expandió sobre todo a partir de 1900. El primer Congreso Internacional de Eugenesia tuvo lugar en Londres en 1912, pero ya en 1907 el estado de Indiana en los Estados Unidos había comenzado a aplicar leyes de esterilización a cierta clase de enfermos ${ }^{66}$. El movimiento eugenista, que mucho tuvo de cruzada biológico-política, se expandió por América Latina; puede señalarse la presencia de esas ideas o instituciones eugenistas, en 1913 en el cuerpo médico brasileño, en 1918 en el argentino y en el Uruguay desde las primeras décadas del siglo XX. En diciembre de 1927 se realizó en La Habana la Primera Conferencia Panamericana de Eugenesia y Homicultura, con la participación de 16 países, entre ellos Uruguay. Las resoluciones de esta Conferencia proporcionan el programa del eugenismo americano muy influido por el estadounidense. Primero se insistió en que las naciones de América dictaran leyes de inmigración «destinadas a impedir el ingreso a sus territorios de representantes de razas cuya asociación se considera biológicamente indeseable», por lo que las naciones americanas tendrían el derecho de establecer medidas «para conservar la pureza racial de su descendencia». La defensa de la raza humana se había transformado claramente en defensa de la raza dominante. En segundo lugar, se recomendó que las autoridades encargadas de autorizar los matrimonios, exigieran «a cada uno de los cónyuges su historia biológica, la que pondrán a disposición del otro cónyuge o del jefe de familia». Las condiciones germinales de los individuos se clasificarían en «bueno, dudoso y malo», pero los individuos también se clasificarían «somáticamente» en responsables de dirigir su vida procreativa o irresponsables de hacerlo. Los responsables con condiciones «buenas» podrían dirigir su vida procreativa «cuidando de las condiciones de sus cónyuges»; a los portadores de condiciones «malas o dudosas», pero responsables, se les permitiría «previa enseñanza, dirigir su vida sexual bajo la reglamentación que se les indique»; a los portadores de esas mismas condiciones «malas o dudosas» pero irresponsables «se les sometería al aislamiento o segregación o a la esterilización”. Además «la alienación mental, la criminalidad, la sífilis no tratada, el alcoholismo y la narcoma-

\footnotetext{
65 «Reforma proyectada por la Liga Argentina de Profilaxis Social», Boletín del Consejo Nacional de Higiene, julio 1921, pp. 354-356:

66 Cfr. ÁlvareZ PELÁEZ, R. (1985), Sir Francis Galton, padre de la eugenesia, Madrid, CSIC. Debo el conocimiento de estas obras de Alvarez Peláez a Ema Massera.
} 
nía comprobados» después del matrimonio, podrían ser motivos de su «anulación», pudiendo realizarse «esa comprobación no solo por el otro cónyuge sino por autoridad competente».

En tercer lugar se votaron resoluciones que tendían a «proteger» a las mujeres embarazadas y a los niños. La mujer embarazada estaría «obligada» a seguir las prescripciones médicas, pero tendría derecho al reposo pre y post parto; «la madre nodriza» tendría «el deber y el derecho a poder amamantar a su hijo durante un año» y éste «el derecho natural al seno de su madre durante los 8 primeros meses de su vida». El cultivo del desarrollo físico y mental de los habitantes de cada nación americana completaba este conjunto de recomendaciones a los gobiernos.

En noviembre de 1934 se realizó en Buenos Aires la Segunda Conferencia Panamericana de Eugenesia y Homicultura. El Presidente argentino, General Agustín P. Justo, la inauguró, y concurrieron, como delegados oficiales del Uruguay, los médicos Roberto Berro y Víctor Escardó y Anaya. Esta conferencia reiteró el consejo de los gobiernos y municipios de establecer «consultorios especiales para el examen médico prenupcial» a los cuales se presentarían, eso sí, «voluntariamente», los interesados, y también la recomendación a los gobiernos de «reservarse [el derecho] de examinar las ventajas de la entrada de la corriente inmigratoria», ajustándola a «sus intereses económicos, políticos y sociales». Esta segunda conferencia, desarrollada en plena crisis económica mundial, insisitió más que la primera en la necesidad de la estabilidad de los empleos de «los padres de familia» y brindó un «voto de aplauso» al Uruguay por su «Código del Niño» en el que se halló el comienzo de un verdadero «código biológico del hombre» que mejoraría la perpetuación de la raza ${ }^{67}$. El eugenismo americano se identificó así con la preservación de la pureza de la «raza» dominante en cada país americano — sobre todo se pensó en la blanca en América Latina y en los blancos anglosajones en Estados Unidos- y también reveló aristas totalitarias por cuanto procuró subordinar el derecho individual de casarse y procrear, a una decisión a menudo estatal, en manos, esos sí, de biólogos. Pocas veces la utopía «científica» había concluído en un movimiento tan sospechosamente ligado a ciertos postulados de la derecha política. Tal vez fuera por el contexto de temores que lo hizo nacer.

El sentimiento clave de la eugenesia era el miedo a la «degeneración» de la especie o la raza. El pesimismo sobrevenía cuando se comparaba lo que se creía había sido el hombre primigenio o «ancestral» —este término encantaba a Mateo Legnani-con el espectáculo de enfermedad, miseria y violencia coaligados que caracterizaba a las masas urbanas hijas del desarrollo capitalista. Todos los médicos del No-

67 Cfr. Alvarez Peláez, R., (1988) « Eugenesia y control social», Asclepio, XL, (2), pp 29-80; ZIMMERMANN, Eduardo A. «Raza, medicina y reforma social en la Argentina, 1890-1920», en A. Lafuente, E. Elena y M.L. Ortega (editores): «Mundalización de la ciencia y la cultura nacional», Madrid, Ed. Doce Calles, 1993. Agradezco a su autor el conocimiento de este artículo. 
vecientos creyeron que el hombre estaba al borde de su desaparición o transformación en especie inferior, sobre todo por los efectos combinados del alcoholismo, la sífilis y la tuberculosis. La visión de la «clase médica» era apocalíptica. En 1898, el facultativo argentino F. Correa Llobet sostuvo que «la degeneración de la humanidad y la organización física y moral del hombre» eran un hecho indiscutible testimoniado por un sinnúmero de datos verificables, por ejemplo que «la vida media del hombre moderno es mucho más reducida que la del hombre antiguo. Ya no se oye hablar de aquellos que mueren a los 80, 90 o ciento y tantos años ${ }^{68}$ ». En 1915, Mateo Legnani afirmó parecidos conceptos y argumentos con una nota dramática todavía más cargada de pesimismo: «La Humanidad va por mal camino ahora [...] la especie irá acentuando de generación en generación todas y cada una de sus taras, predisposiciones mórbidas y enfermedades[...] acortando el promedio de duración de su existencia, deformando y desviando su tipo [...] viciando el temperamento, agotando el brío, aminorando las resistencias». El problema era que la «diátesis» o predisposición orgánica a contraer enfermedades, resultaba «cada vez más espesa, más cargada». «Los sucesivos ataques de las enfermedades van cambiando la nutrición, el metabolismo [...] minando, sobre todo, el sistema nervioso ${ }^{69}{ }_{\gg}$.

El temor ganó vastos núcleos intelectuales. En 1920, Manuel Medina Betancourt lo expresó desde el diario La Razón en frases lapidarias: «si lo bueno continuara mezclándose a lo malo, la materia enferma seguirá corrompiendo a la sana y poco a poco el género humano desaparecerá disuelto en un dantesco mar de podredumbre». La frase final era de un darwinismo elocuente y agresivo: «Las especies que no saben defenderse, desaparecen ${ }^{70} \gg$. Este pesimismo sobre el futuro de la especie $\longrightarrow$ de la raza-, típico en el saber médico del período 1870-1940, sobrevenía cuando se observaba el espectáculo de los seres alcoholizados, hambrientos y violentos, notorios en las muchedumbres proletarias. Mateo Legnani lo describió así en 1915: «Los caracteres de degeneración vulgarizados por Lombroso se constatan con una frecuencia tal, que ya han perdido su valor jurídico. El médico legista los encuentra en todos lo acusados, y al proyectar la mirada en redor, los ve en los miembros del tribunal, en el público que acude a los juicios, en los periodistas que hacen las crónicas, en el fiscal [...]. Allí un gordo apático, aquí un flaco ticoso o coreico, allí un labio de escrofuloso eternamente resfriado, allá un prognata, acullá una nariz chata, estigma del Schaudinn paterno [la sífilis]. La tuberculosis y la sífilis por doquiera, y por doquiera el alcoholismo. Evidentemente, las masas eran feas y provocaban temor.

A los ojos de esta élite científica de mentalidad burguesa, esos seres hacían correr a la humanidad el más grande de sus riesgos. Salvarlos tal vez, pero también y sobre

\footnotetext{
68 CORREA Llobet, F. (1898), ¿Puede casarse un sifilítico?, Buenos Aires, Imp. Galileo, pp. 81-83.

69 LEGNANI, Mateo, (1915), Ensayos de higiene social, pp. 34-38 y 102.

70 «El proyecto sobre profilaxia matrimonial», (1920), La Razón, (diario de Montevideo), 13 julio, p. 7 , cols. 1 a 6 .
} 


\section{BIOLOGÍA, MEDICINA Y EUGENESIA EN URUGUAY}

todo, controlar su reproducción, era función de la Higiene y el saber médico. El miedo a los de abajo se transformó en angustia por el futuro de la especie o la raza. Este temor actuó como trasfondo incluso en los médicos «progresistas» que apoyaban, como hemos comprobado, la reforma social. La raíz social burguesa y conservadora del eugenismo también se aprecia en su tendencia a confundir preservación de la especie humana con defensa de la raza dominante, la blanca, argumentándose a veces que en ella residían los mejores ejemplares para proceder a la selección natural. ¿Acaso el éxito de los «señores» no probaba su superioridad biológica? Este racismo ligado al miedo a las muchedumbres, notorio en el eugenismo estadounidense, se advierte sólo a veces en el caso uruguayo y probablemente se vincule a ese sentimiento de identificación con Europa, típico de un pueblo que todo él se creía descendiente de inmigrantes de ese origen. En 1918, Mateo Legnani expresó esta concepción con su peculiar estilo: «Para el higienista [...] salud es la ancestral [...] cuya vitalidad derrotó la vitalidad de todas las razas [...] acaparó a todos los hombres, y llega al hombre europeo». Por ello a ese hombre lo caracterizaba la «sinceridad [que] brotaba de la convicción íntima, consciente o no, de poder, de vigor, de salud, [mientras] la astucia, cualidad dominante en razas inferiores, [caracterizaba a] indios y negros, con quienes no ofrece grandes similitudes, por cierto, al ancestral de que desciende el hombre hacedor de la civilización ${ }^{71}$ ».

Pero el racismo uruguayo no pasó de ser una expresión minoritaria, al menos, si recurrimos a los testimonios escritos de su existencia. En cambio, entre los temores causantes del eugenismo jugó un rol muy importante en Uruguay la comprobación de que la abstracta «degeneración» de la especie o la raza encarnaba, en realidad, en la ruina de la familia burguesa, pues ella también se veía amenazada por la introducción en su seno de la enfermedad. En ese momento de crisis de la familia tradicional, en que la mujer reveía su rol y el divorcio se entronizaba -la primera ley de divorcio es

71 LEGNANI, Mateo, (1918), pp. 73-74 y 101. En algunas ocasiones, el eugenismo uruguayo, incluyó a las manifestaciones más destacadas de la cultura en el concepto de degeneración, con lo cual se acercó, probablemente sin sospecharlo, a los rasgos conservadores de la mentalidad pequeño-burguesa que el nazismo entronizaría en los años treinta en Alemania.Tan temprano como en 1915, Mateo Legnani creyó advertir en el art nouveau otro testimonio de la degeneración de la especie: «Y no se echa de ver que si prosperan tales artes es porque tienen un público decadente, cuya alma esta mordida, viciada, extraviada, por la decadencia nerviosa, por degeneración colectiva» (Cfr. LEGNANI, Mateo, (1915), pp. 94-95). Manuel Medina Betancourt, partidario apasionado del eugenismo, opinó de manera similar en 1920, pero abarcó en su condena de lo degenerativo a más actividades humanas contemporáneas suyas: «Corremos demasiado hacia las fronteras del desorden orgánico espiritual, hacia un funesto extremo disolvente. [Vemos así] en política, en arte, en sociología, primando las ideas más absurdas y más anárquicas, donde los valores que formaban hasta el presente todo el bagaje de la civilización, toda nuestra ciencia experimental y toda nuestra razón, solo sirven para ser escarnecidos y negados». (La Razón, 13 julio 1920, p. 7 cols. 1 a 6.). Esta indignación. ¿la despertaban el cubismo, el surrealismo, el comunismo y las ideas de Freud? Muy probablemente. Si es así, ella revelaría la intolerancia y la fe militante de un antiguo positivista, sorprendido por la evolución de la cultura occidental luego de 1900. 
de 1907- también la enfermedad amenazaba la cadena de las generaciones. De ese modo, la trasmisión de la herencia y el poder al heredero hijo de alcohólico, sifilítico o tuberculoso, se convertía en una burla a la institución familiar. Los sifilógrafos, en particular, tuvieron muy presente ese riesgo de la especie que para la familia significaba la muerte. La heredo-sífilis del medico francés Alfredo Fournier implicaba la creencia en la perpetuación de la enfermedad «hasta la enésima generación», por lo que, a la vez que se reafirmaba la cadena familiar, se provocaba angustia al ponerse en duda la posibilidad biológica de su continuidad. Por ello en todas las historias clínicas se preguntaban los antecedente hereditarios con especial referencia a la sífilis, la blenorragia, la tuberculosis y el alcoholismo. Obsérvese esta preocupación por el destino de la familia en las palabras del médico francés Arturo Vernes que el Consejo Nacional de Higiene tradujo en 1921: «La sífilis es causa de despoblación y de degeneración de la raza [...] así sucede que se multiplican las familias [...] cuyos miembros padecen de taras o dolencias, sordera, ceguera, debilidad mental, hidrocefalia, epilepsia [...] que las hacen socialmente inútiles y que pueden ellas mismas trasmitir a sus descendientes, haciendo las veces de tronco de degenerados ${ }^{72} \gg$. Esta destrucción por la enfermedad del «germen de la estirpe» - expresión de Paulina Luisi en $1916^{73}$ - hacía temer el fin del poder de la familia burguesa, la ruina biológica que anunciaría la ruina económica y social.

También indicaremos entre las causas de la difusión del eugenismo, otro hecho visible en Uruguay: el temor al «mancillamiento» de la mujer virgen por el marido enfermo, miedo de todos los padres de hijas casaderas que prometía conjurar la medida eugenista más popular: el certificado de salud prenupcial a exigir a los dos contrayentes, pero, sobre todo, al hombre joven.

Paulina Luisi en 1916 y 1919, los folletos del Instituto Profiláctico de la Sífilis de 1922 y Héctor del Campo en 1923, hicieron expresa referencia «a las desgraciadas esposas contaminadas [por esos] jóvenes ignorantes [que les regalaban] con la consagración nupcial , la gonorrea o la sífilis ${ }^{74} \gg$. Pero era Alejandro Gallinal, el médico católico que presidía el Instituto Profilático de la Sífilis, que siempre que recorría como conferencista los liceos del interior del país para prevenir a los jóvenes de los contagios venéreos, sacaba a relucir el rencor de los padres ante la entrega de sus

\footnotetext{
72 Boletín del Consejo Nacional de Higiene, mayo 1921, pp. 273-274. P.C.M.N. Tomo II, p. 311: RODRÍGUEZ, J.A. art. cit.

73 LUISI, Paulina, (1920), Enseñanza sexual, Montevideo, El Siglo Ilustrado, pp. 19-20.

74 LUISI, Paulina, (1919), A propósito de los proyectos sobre moralidad, Buenos Aires, Perrotti, pp. 12-13. Id. id.: «La trata de blancas y el problema de la reglamentación», ob. cit. p. 47. PROFESOR FOURNIER: «para nuestros jóvenes», ob. cit. B.C.N.H. febrero 1923, p. 122: Hétor del Campo, art. cit.
} 
hijas a esos yernos. Decía: « ¿Uno tiene una hija a la cual cuida como una flor y viene un canalla y la ensucia para toda la vida! ${ }^{75}$ ».

Por último, debemos señalar que el mensaje eugenista tuvo mucho de factor religador de la sociedad a través de una nueva utopía, en una época en que la religión, debilitada, ya no movilizaba las conciencias ni inventaba las solidaridades. El eugenismo creó un mensaje colectivo dinamizador de militancias, y proporcionó una fe que se vestía con el único ropaje que en el Novecientos legitimaba, el lenguaje científico.

\subsection{El eugenismo uruguayo}

La primera nota característica del eugenismo uruguayo fue su preferencia por el uso del término «especie» y no «raza», aunque existieron, como hemos visto, excepciones, y de monta. Ese acento en la defensa de la especie humana y no de la raza específica del país, revelaba la presencia, también en el discurso científico, de ese nacionalismo cosmopolita que era el rasgo propio de la conciencia nacional, acabada de forjar precisamente en ese Novecientos y moldeada por el batllismo en la admiración a lo europeo. El médico uruguayo, puesto a pensar en esterilizar a los enfermos y permitir solo la procreación de los sanos, tenía, por lo general, en vista a la humanidad, no a su República que, por otro lado, taampoco llamaba «nación». El caso más ilustrativo a este respecto es el de Paulina Luisi, como observaremos. La segunda nota del eugenismo uruguayo fue su obsesión por el efecto «destructor de nuestra especie» que tenía el «triunvirato» de enfermedades compuesto por «la sífilis, el alcoholismo [y] la tuberculosis», según gráficas expresiones de Paulina Luisi en $1919^{76}$. Alcoholismo y sífilis se disputaron el primer lugar de la obsesión.

Sebastián B. Rodriguez en 1913, Bernardo Etchepare en 1915 y Paulina Luisi en 1919 , creyeron que el alcoholismo no solo preparaba «el terreno» para la tuberculosis sino que también, «disminuía y suprimía a la larga [...] la vitalidad de la raza por intermedio de su descendencia, engendrando hijos idiotas, imbéciles, paralíticos, etc., impropios todos para la reproducción de la especie». Etchapare fue terminante: «[las] 4/5 partes de los [hijos de bebedores] que sobreviven se vuelven epilépticos o criminales y el resto, a su vez, sufriendo la pena del atavismo, se hacen bebedores. Tal es la herencia alcohólica en su rigidez inexorable». Concluyó con una nota personal y aterrorizadora estos conceptos que eran, en realidad, «consejos a las madres»: «Todos los días veo ingresar al Manicomio bebedores adolescentes: son todos hijos de

\footnotetext{
75 Testimonio en carta dirigida al autor del Prof. Ariel Dieste de 3 de abril de 1991, en que hace referencia a sus recuerdos del departamento de Artigas entre 1920 y 1930.

76 LUISI, Paulina, (1919), Para una mejor descendencia, Buenos Aires, Perrotti, pp. 12-17.
} 
alcoholistas ${ }^{77} \gg$. En 1909, el médico Carlos Brito Foresti presentó a la Sociedad de Medicina de Montevideo un caso de «ginecomastia» y lo atribuyó al «alcoholismo paterno [pues] el alcoholismo [...] es el alfa y el omega de todas las degeneraciones [...] y el alcoholista puede engendrar degenerados; uno será desequilibrado, otro será un demente y alguno saldrá malformado, será ginecomasta ${ }^{78}$ 》. El alcoholismo, el primer vicio "POPULAR", era la causa tal vez más clara de la ruina de la especie.

Pero la sífilis podía disputarle ese rol. Mateo Legnani en 1915 y Paulina Luisi en 1919 lo creyeron así. Paulina Luisi fue una de las denunciadoras más destacadas de sus efectos sobre la especie: «Es un verdadero Moloch de dos embriones: es la gran fautora de abortos y de nacidos muertos, es la preparadora de millares de criaturas enfermas, deformes o monstruosas, idiotas e hidrocéfalas. La sífilis, más que el alcoholismo, más que la tuberculosis, más que todas las enfermedades juntas, es la verdadera enemiga de la especie». Una gran cantidad de hijos de sifilíticos eran «felizmente estériles» pero... no todos, por desgracia ${ }^{79}$. A eso conducían la sexualidad no controlada por el «Amor» en la madurez, y por la continencia en la adolescencia, y la miseria social y fisiológica de la prostitución. Tal era, en apretada síntesis, la opinión de la médica socialista.

De estas posiciones el eugenismo uruguayo dedujo su principal línea de acción: el control de la procreación en procura de que sólo los sanos engendrasen y a los enfermos se les prohibiera casarse o se les esterilizara. Realicemos una exposición cronológica de esta idea que servirá, a la vez, para datarla y medir su progresiva difusión social. En 1907 apareció en la revista órgano de la Sociedad de Medicina de Montevideo, un comentario bibliográfico de Juan Pou Orfila a la obra de un médico alemán donde éste se preguntaba si se debía «practicar la esterilización de las mujeres enfermas o con deformidades, débiles y extenuadas [que no ofrecían] seguridad ninguna desde el punto de vista de la robustez de su descendencia»; había que tener en cuenta «desde el punto de vista social y político, que donde no había madre sana, [existía] forzosamente decadencia en la prole [por lo cual] debían excluirse de la maternidad todas las mujeres que no fueran perfectamente sanas». Juan Pou Orfila sólo realizó una reseña y no enjuició el contenido del libro alemán por lo cual no conocemos a ciencia cierta su opinión personal ${ }^{80}$. Pero al año siguiente, en 1908, el tisiólogo Roberto Berro propuso claramente «la esterilidad individual del tuberculoso»; debía tenerse en cuenta «que las razas progresan siempre por las buenas cuali-

77 ETCHEPARE, Bernardo, (1915), La lucha contra el alcoholismo, Montevideo, El Siglo Ilustrado, p. 5; LUISI, Paulina, (1919), Para una mejor descendencia, Buenos Aires, Perrotti, pp. 12-17. Rodríguez, S.B., (1913), «El factor alcohol como factor de despoblación», La Tuberculosis, marzo, pp. 38-39.

78 BRITO FORESTI, Carlos, (1909), «Un caso de ginecosmastia», Revista Médica del Uruguay, pp. 1-6.

79 LegnanI, Mateo, (1915), p. 90; LUISI, Paulina (1919), Para una mejor descendencia, p. 17-23.

80 POU ORFILA, Juan, (1907), «Bibliografía obstétrico-fisiológica extrangera: Mensigna», Revista Médica del Uruguay, p. 29. 


\section{BIOLOGÍA, MEDICINA Y EUGENESIA EN URUGUAY}

dades físicas de los procreadores aunque pocos, y no por la abundancia de reproductores que procrean multitudes débiles y enfermas que caerán abatidas [...] para construir un serio elemento de degeneración social ${ }^{81}{ }$. El elitismo de Roberto Berro afloraba en su adjudicación de las bondades físicas a los «pocos», el uso del término «raza», y su condena de los reproductores «abundantes» que solo generaban «multitudes débiles y enfermas», obvia referencia a las masas miserables, alcoholizadas, tuberculosas, sifilíticas y ... violentas. También en 1908, Augusto Turenne, a fin de evitar la degeneración de las proles, aconsejó a sus colegas «prohíban energéticamente uniones que solo asegurarán descendencias de valor problemático»; incluso admitió que «en la posibilidad de prevenirlas podría aun el médico exigir practicas anticoncepcionales ${ }^{82} \gg$.

En 1912 el Consejo Nacional de Higiene envió como delegado al II Congreso Español de la Tuberculosis, celebrado en San Sebastián, al facultativo Constancio Castels. Las conclusiones del congreso fueron sugestivas: en vista de las «consecuencias funestas» que podía determinar la tuberculosis en la descendencia, se recomendaba a «los Gobiernos [que] pensaran seriamente en la necesidad de que la ley establezca limitaciones en la celebración del matrimonio entre individuos tuberculosos ${ }^{83} \gg$. Estas ideas se difundieron rápidamente en la «clase médica» y buena parte de la sociedad uruguaya, angustiada por ese renacimiento del pecado original que maldecía a los hijos inocentes, ahora bajo la especie científica, en el preciso momento en que la sociedad creía haber olvidado la culpa cristiana pues estaba secularizando su mentalidad.

En 1916, en el Primer Congreso Médico Nacional, Juan Giampietro propuso a sus colegas «evitar las uniones matrimoniales de personas con enfermedades hereditarias trasmisibles», y aunque aun creía que ello debía suceder «espontánea y voluntariamente», propició «la idea salvadora de la visita al médico antes de la unión matrimonial [entonces] sería factible conseguir lo que se busca: la selección de la semilla ${ }^{84}$ ». Mateo Legnani en sus ensayos de 1917 y 1918 apoyó con su peculiar misoginia estos principios: las mujeres, por su educación, no sabían elegir pareja y juzgaban al hombre por su aspecto y posición social cuando lo que interesaba era su salud y vigor: «Las prerrogativas concedidas al sexo femenino [...] son enormes, y a pesar de que su poder de raciocinio es menor que el del sexo masculino, la mujer es la que íntimamente dirige la selección en la formación del hogar». Su programa incluía la educación de las mujeres para que eligiesen según criterios biológicos a sus parejas, y

81 BERRO, Roberto, (1908), «Cómo debe ser un sanatorio para tuberculosos», La Tuberculosis, marzo, pp. 87-88.

82 TURENNE, A., (1908), «Higiene del embarazo», Revista Médica del Uruguay, pp. 215-216:.

83 CASTElls, Constancio, (1913), «Informe», Boletín del Consejo Nacional de Higiene, febrero.

84 GiAMPIETRO, Juan, (1917), «Principales medios de lucha contra la mortalidad infantil», Primer Congreso Médico Nacional, Tomo II, p. 738. 


\section{JUAN PEDRO BARRÁN}

«dejar que el tuberculoso, el sifilítico, el degenerado, murieran pronto y sin prole, [o] impedirles la procreación» de algún modo ${ }^{85}$.

Paulina Luisi no se afilió al intervencionismo del Estado en esta materia íntima, pero en 1919 señaló el deber de las parejas de actuar con «responsabilidad genésica», para lo cual se imponía «la educación sexual» y así evitar las uniones de enfermos que solo podían conducir a «vidas inútiles y perjudiciales». En 1925 llegó a preguntarse «si no vale la pena ensayar [...] métodos que consigan la esterilización de los enfermos venéreo-sifilíticos, empleando formas de acuerdo con lo que exige la profilaxis ${ }^{86}$ ».

En 1920 el diario La Razón inició una campaña periodística en defensa del proyecto de ley sobre «profilaxis de la familia» que había presentado a las Cámaras, como simple ciudadano, Manuel Medina Betancourt, batllista de nota, periodista de El Día y novelista. El contenido del proyecto, que no conocemos en detalle, deducido de las declaraciones de su autor al citado diario, pretendía «defender a la familia y a la especie [evitando] el matrimonio de individuos enfermos, seres que por leyes biológicas [...] no podrán dar otra cosa que desventurados frutos débiles, predispuestos o degenerados». Los casamientos se permitirían siempre que el médico certificara en un examen prenupcial la inexistencia de una serie de enfermedades entre las que se incluían «naturalmente», alcoholismo, sífilis y tuberculosis, pero según parece también otras consideradas hereditarias como cáncer y lepra. Medina Betancourt a posteriori sumó la blenorragia a esa lista y lo hizo a expreso pedido de un médico. El diario La Razón, en sucesivos artículos a lo largo de por lo menos diez meses (julio 1920 a abril de 1921), publicó opiniones médicas casi todas favorables al proyecto, entrevistas varias a su autor y noticias sobre cómo la idea ya se había convertido en ley en diversos estados de la «Unión», tales Pennsilvania, Oregón y Wisconsin. La ley vigente en Pennsilvania desde 1913 pareció al periódico particularmente atractiva: «ninuno de los contrayentes estará afectado de enfermedad trasmisible o contagiosa. No se otorgarán permisos para casamientos en los casos en que alguna de las partes sea un imbécil, o epiléptico o tenga las facultades mentales alteradas [...] o si en el momento está bajo la influencia de bebida alcohólica ${ }^{87}$ ».

85 LEGNANI, Mateo, (1917), p. 105 y siguientes; Ibid. (1918), pp. 125 y siguientes.

86 LUISI, Paulina, (1919), Para una mejor descendencia, pp. 12-17 y 27-29; Idem., (1925), El problema de la prostitución? Abolicionismo o reglamentarismo?, Montevideo, Sindicato Médico del Uruguay, p. 31.

87 La Razón, diario de Montevideo, 13 julio 1920 , p. 5 , cls. 1 a $6 ; 15$ octubre 1920 , p. 1 , cls. 4 y 5 y p. 2 col. 1 y $2 ; 19$ enero 1921 , p. 1 , cls. 5 y 6; 21 enero 1921, p. 3, cls. 1 a 3; 10 febrero 1921, p. 2, cols. 4 y $5 ;$ y 12 abril 1921 p. 2 cls. 5 a 8 . Algunos sectores de la sociedad uruguaya ya habían hecho suya esta preocupación eugenista y era cada vez más común que las familias se otorgaran certificados de salud prenupciales. En ciertos medios burgueses, la exigencia de los mismos a los novios varones llegó a transformarse en hábito elogiado por sensato. Miguel Becerro de Bengoa, médico, y Manuel Medina Betancourt, hicieron referencia en 1920 a «los médicos que los otorgaban a veces también por dinero» $L a$ Razón, diario de Montevideo, 28 septiembre 1920, p. 5, cols. 3 a 5; 1 octubre 1920, p. 1, cols. 5 y 6 y p. 
En 1921, Mateo Legnani presentó como diputado un proyecto inspirado en las ideas de Medina Betancourt pero sin sus demasías. Legnani comenzaba afirmando el derecho de la sociedad «a intervenir en la reprodución de la especie de suerte que solo los sanos dejaran herencia fisiológica», pero advirtió que el saber médico no había llegado aún a definir con exactitud cuáles dolencias eran nefastas a la especie, excepción hecha de la sífilis, por lo cual era correcto «exigir un certificado de reacción Wassermann negativa al que quiera contraer matrimonio».

Añadió, como buen batllista anticlerical: «de todos modos, es evidente que someterse a ella ha de ser obligación civil más útil y aceptable que la "confesión", exigencia previa y corriente del matrimonio religioso». Esta transformación de la confesión católica en Wassermann laico es, de seguro, un interesante aporte del saber médico uruguayo a la laicización de la cultura occidental y a la medicalización de la moral que el saber médico estaba iniciando por esos años.

En octubre de 1927, el Consejo de Administración de Montevideo autorizó a la Clínica Preventiva Municipal dirigida por el médico Enrique M. Claveaux, a otorgar certificados de salud a las personas que los solicitasen y se propusieran contraer enlace, previa realización del Wassermann y a un costo de un peso. En abril de 1934, el gobierno de Gabriel Terra aprobó el Código del Niño a que ya aludiéramos, en cuya elaboración se destacaron los médicos Roberto Berro, Luis Morquio, Julio A. Bauzá y Víctor Escardó y Anaya, y la abogada feminista Sofía Alvarez de Demicheli, esposa del Ministro del Interior del dictador. En ese Código se consagró la principal medida eugenista de la legislación uruguaya, pues su artículo 27 indicaba hacer «propaganda persuasiva para obtener la mayor concurrencia de futuros cónyuges a los "Consultorios Médicos Prenupciales", a cargo del Ministerio de Salud Pública». Los oficiales del Registro del Estado Civil, por su lado, «aconsejarán a los futuros cónyuges acerca de la ventaja de la consulta prenupcial dejando constancia en el acta de la inscripción de haberlo hecho asi ${ }^{88}$ ».

En la década 1930-40, algunas posiciones médicas extremas sobre «profilaxia de la familia», recuerdan a los modelos europeos autoritarios, cuando no definitivamente nazi-fascistas. En 1930, el neuro-psiquiatra José María Estapé, Director de la Cárcel Penitenciaria desde 1933, al referirse a «la lucha contra la degeneración mental», luego de aludir a la prohibición del enlace matrimonial a «las personas portadoras de una tara degenerativa», mencionó «otro recurso de la profilaxia: la castración de [las] personas». Declaró: «en el hombre se puede realizar facilmente irradiando

\footnotetext{
2, cols. 2 y $3 ; 25$ octubre 1920 , p. 1 , cols. 5 y 6 y p. 2 c. $1 ; 28$ octubre 1920 , p. 3 , cols. 1 a $4 ; 6$ noviembre 1920 , p. 2 , cols. 5 y 6 .

88 LEGNANI, Mateo, ( 1922), Tomo I, p. 77 en adelante. La ordenanza del Consejo Departamental de Montevideo proviene del Archivo Histórico Municipal, Cabildo de Montevideo, y me fue señalada por Marcel Chavez, a quien lo agradezco. El Código del Niño y sus modificaciones en: «Registro Nacional de Leyes y Decretos», Montevideo, Imp. Nacional, 1935, pp. 482 y siguientes del tomo correspondiente a 1934.
} 
los testículos con los rayos $\mathrm{X}$ o con el radio, o si no, ligando el cordón espermático en el canal inguinal; en la mujer se puede realizar irradiando los ovarios, o si no li-

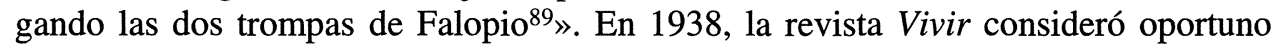
recordar «el derecho y el deber del Estado de mejorar a la estirpe», inhibiendo la función reproductora de «los ineptos», y aunque tales medios le parecieron al autor del artículo, «mas o menos discutibles desde el punto de vista jurídico-moral», confesó que le perturbaban más a efectos de su implantación las dificultades de índole «práctica ${ }^{90}$ ».

Pero el eugenismo uruguayo tuvo también su veta políticamente «progresista», o, si se quiere, las ideologías de izquierda se dejaron influir por el eugenismo y pudieron, en alguna medida, condicionarlo. El primado de la herencia o el medio ambiente en la conformación de las causas de la degeneración de la especie o la raza, dividió al eugenismo. La derecha, con Galton y los eugenistas norteamericanos, sostuvo la influencia decisiva de la herencia, pero el medio ambiente fue ya defendido en época de Galton por médicos europeos y latinoamericanos. La concepción social de la enfermedad, tan predominante en el Uruguay del Novecientos, se vinculó con la idea de que el medio ambiente era el causante de las enfermedades que amenazaban la especie. Sífilis, alcoholismo y tuberculosis no tenían por qué ser genéticamente hereditarias para atacar a la especie, bastaba con que fueran contagiosas y así se enfermaran los hijos. Tal concepción que limitaba el papel de la herencia -notoria ya en la década de 1930-40 - y decretaba, por ejemplo, la ruina científica de la vieja «heredosífilis», devolvió al «terreno» y a la organización social defectuosa, un lugar de privilegio en la etiología de la enfermedad ${ }^{91}$. Además, la izquierda política y los médicos «progresistas» se sintieron atraídos por la capacidad utópica de la eugenesia y el rol que asignaba al Estado en la promoción del mejoramiento de la especie. La tentación de aplicar un programa «científico» y «racial» usando el poder de un Estado que podía llegar a representar a las masas, era demasiado fuerte como para no caer en ella. Derecha e izquierda la experimentaron según, claro está, propósitos diferentes. $\mathrm{Y}$ los médicos vieron en ese programa el tan anhelado gobierno de los sabios y por los sabios a que aspiraban muchos de ellos.

Augusto Bunge (1877-1943), médico socialista argentino, fue un claro exponente de este eugenismo «progresista». El periódico uruguayo El Socialista más de una vez lo citó. En marzo de 1919 transcribió, por ejemplo, estos conceptos de su autoría: «Es verdaderamente de una triste incoherencia gastar millones en palacios para albergar enfermos incurables o degenerados, enfermos que están poco menos que fuera de la humanidad, y permanecer de brazos cruzados frente a los sufrimientos de la

89 ESTAPÉ, José María, BALETTA BIANCHI, Julieta, (1930), Introducción al estudio de los niños mentalmente anormales, Montevideo, Monteverde, pp. 303-304.

90 R.V. (1938), «El certificado. La vista de conjunto», enero, pp. 268-269.

91 R.V. (1938), «El papel de la herencia», febrero, p. 310. 


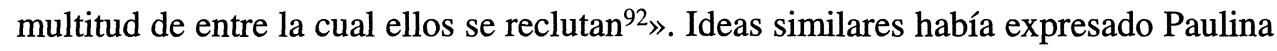
Luisi en sus escritos.

El eugenismo predicaba igualmente y con insistencia, el cuidado de la madre embarazada y los derechos de los niños, y desde este ángulo también lo adoptó la medicina «progresista». Los pediatras, en particular, se entusiasmaron con la defensa de la especie a través del amparo y la protección de la infancia, testimonio de lo cual fue ese voto de aplauso que recibió el Uruguay por su Código del Niño en la Conferencia de Eugenesia de 1934. En mayo de 1919, el II Congreso Americano del Niño, reunido en Montevideo, había proclamado que «la protección del niño hasta la terminación de la adolescencia» era la gran garantía del «perfeccionamiento integral de la raza». El mismo Congreso apuntó a otro argumento que los eugenistas utilizaban: el control de la natalidad. Pero el Congreso apostó no tanto a la supresión de la descendencia de los enfermos sino al control de la «superabundancia» que podía «ser causa de perturbación para la salud y engendrar mentalidades no deseables en una sociedad bien organizada [...] El porvenir de la especie exige la profilaxis de la miseria y de la superabundancia ${ }^{93}$ ». El eugenismo, en realidad, invocaba siempre el control de la natalidad, lo que Paulina Luisi llamaba en 1919, actuar con «responsabilidad genésica». Limitar el número de niños podía significar, tanto menos «taras hereditarias», como menos candidatos a la miseria... y a la rebeldía.

La documentación reunida testimonia que el eugenismo o sus ideas claves lograron muy importante difusión e influencia en el Uruguay desde 1900 a 1940. Sifilógrafos y pediatras, con Luis Morquio a la cabeza, elogiaron a Galton y consideraron imprescindible «el certificado de buena salud para el matrimonio ${ }^{94}$ ». El diario $\mathrm{La}$ Razón, al realizar una encuesta entre los médicos sobre el proyecto de Manuel Medina Betancourt, halló que las respuestas eran ampliamente favorables a la iniciativa. Erasmo Arrete, Jaime Nin y Silva, Alfredo Pérsico, Francisco Brito del Pino, Rafael R. Rodríguez, E. Torres Grané, Joaquín E. Travieso y Atilio Narancio, agregaron razones de su propia cosecha. Francisco Brito del Pino opinó: «Que ni el degenerado mental, ni el alcoholista ni el canceroso puedan impunemente contribuir al nacimiento de razas raquíticas, epilépticas, con taras [...] y puedan procrear hijos sanos los que son sanos de cuerpo y alma», y el especialista en enfermedades de la piel y venéreas, Joaquín E. Travieso, propuso incluir la blenorragia entre las enfermedades que excluirían del matrimonio. Solo Miguel Becerro de Bengoa se opuso por considerar

92 BUNGE, Augusto, (1919), «La higiene social en la escuela», El Socialista, periódico de Montevideo, 26 de marzo, p. 2, col. 5 ; p. 3, col. 1 .

93 II Congreso Americano del Niño, Boletín del Consejo Nacional de Higiene, junio 1919, pp. 615-617.

94 MORQUIO, Luis (1916), Protección a la primera infancia, Montevideo, El Siglo Ilustrado, pp. 1617. II Congreso Sudamericano de Dermatología y Sifilografía, Boletín del Consejo Nacional de Higiene, octubre 1921, pp. 569-576.. 


\section{JUAN PEDRO BARRÁN}

cruel la medida, aunque opinó que: «la esterilización de esos enfermos, sin mutilaciones, permite el matrimonio que es difícil y peligroso negar [y] conserva el amor ${ }^{95}$ ».

En los años veinte y treinta de este siglo el eugenismo influyó en la educación estatal. Hacia 1935, el texto de enseñanza de Higiene y Biología del médico Francisco Brito del Pino, insistía en «los efectos desastrosos del alcohol en la descendencia» familiar y «la especie humana ${ }^{96} »$. En la cátedra de higiene infantil y puericultura que se dictaba en los Institutos Normales, el pediatra Américo Mola lo implantó oficialmente en 1925, y en su texto de 1932, que utilizaba para formar a las futuras maestras y llegar así al público infantil, decía: «Los principios sustentados por el Eugenismo, esa ciencia nueva que estudia lo que se relaciona con el porvenir y la raza, [..] deben ser aplicados en la medida posible, como base del perfeccionamiento de la raza». Por ello se lamentaba de que en el Uruguay todavía no se hubiera legislado para «impedir la procreación a seres tarados por estados patológicos (sífilis, tuberculosis y alcoholismo) que tan grave influencia ejercen sobre el producto de la concepción y sobre las condiciones vitales del futuro $\operatorname{ser}^{97}{ }_{\gg}$. El uso del restrictivo término «raza» merece ser destacado.

Con las ideas eugenésicas, la construcción - ¿o invención?- del cuerpo por el saber médico dió un paso adelante gigantesco. Ese saber ahora pretendía - y en ciertos países y sectores sociales ya había logrado- aplicar sus principios a la especie o la raza, modelándolas de acuerdo con su idea preconcebida de lo sano y lo enfermo. En este caso, lo sano se parecía, sospechosamente, a lo fuerte y lo triunfante, a las «razas», los países y las clases dominantes, y lo enfermo, a lo débil y fracasado, a las «razas», los países y las clases dominadas. Un Nietzsche aburguesado rondaba por allip8.

95 La Razón, diario de Montevideo, 20 de julio de 1920, p. 6, cls. 3 a 5; 17 de agosto ded 1920, p. 1, cls. 3 y 4; 20 de agosto de 1920, cls. 3 y 4; 24 de agosto de 1920, p. 3, cls. 4 y 5; 31 de agosto de 1920, p. 2, cls. 5 y $6: 3$ de septiembre de 1920, p. 1, c. $2 ; 16$ de septiembre de 1920, p. 1, cls. 5 y 6; 24 de septiembre de 1920 , p. 1 , cls. 5 a 7 y p. 2, c. $1 ; 13$ de novimebre de 1920 , p. 1 , cls. 3 a 5.

96 BRITO DEL PINO, Francisco, (1935?), Nociones elementales de Higiene y Biología, Montevideo, Comini.

97 Mola, Américo, (1932), Manual de higiene infantil y puericultura, Montevideo, Imp. Uruguaya, pp. 63-68.

98 Hoy en día (1999) la eugenesia ha renacido, aunque la decisión acerca de cuáles son los seres humanos «inferiores» que deben ser eliminados no está en manos del Estado -como en la Alemania nazisino del consejo médico y las parejas. Los certeros diagnósticos prenatales (amniocentesis y exploración por ultrasonido del vientre materno) permiten detectar los fetos anormales (con síndrome de Down, por ejemplo) y desecharlos por medio del aborto. 